\title{
A Single Initiating Cause of Hypertension; Potential for Primary Prevention
}

\author{
Mohinder P Sambhi* \\ Professor Emeritus, UCLA School of Medicine, 10390 Wilshire Blvd. Apt. 1405, Los Angeles, CA 90024, USA \\ *Corresponding author: Mohinder P Sambhi, Professor Emeritus, UCLA School of Medicine, 10390 Wilshire Blvd. Apt. 1405, Los Angeles, CA 90024, USA, Tel: 310 \\ 550 6180; Fax: 310550 6342; E-mail: msambhi@adelphia.net
}

Received date: May 15, 2014; Accepted date: August 20, 2014; Published date: August 25, 2014

Copyright: ( 2014 Sambhi MP. This is an open-access article distributed under the terms of the Creative Co mmons Attribution License, which permits unrestricted use, distribution, and reproduction in any medium, provided the original author and source are credited.

\section{Introduction}

Hypertensive Cardiovascular Renal Disease (HCVRD) continuum can be viewed as a disorder of growth and development in higher animals - a non-tumorous proliferative disorder [1]. A higher incidence of cancer in populations with hypertension has been well documented [2].

Peptide growth factors (PGF's) are potent regulators of cell growth from unicellular to complex multicellular organisms. Through a combination of autocrine, paracrine, and endocrine modes of action, PGF's control the activity of all other growth modulators including classical hormones, such as the Renin-Angiotensin-Aldosterone (RAA) system, which they predate on the evolutionary scale [3]. Epidermal growth factor (EGF) and its epidermal growth factor receptor (EGFR), when present, dominate this control through a process of extensive cross talk and transactivation.

The hypothesis for the genesis of HCVRD is first presented in summary form, followed by a brief accounting of supporting evidence. The hypothesis, although evidence based, amply employs a theoretical license. A review of the vast literature on the elusive etiology of HCVRD is beyond the present scope. Hence the citation of the selective references is kept to a minimum and limited to those that relate to the hypothesis. It should be emphasized at the outset that the article is not a literature review of the subject, but is a comprehensive articulation of a hypothesis on the complex subject of the initiation of HCVRD.

\section{Preamble}

A credible hypothesis on the etiology of HCVRD must be in full accord with the well documented "Primacy of the Kidney". It must explain how the kidney is the essential initiating organ as proposed by Guyton [4]. It must identify the unknown "Subtle renal injury" [5] as the fundamental fault which has genetic basis but can also be influenced by several environmental factors, and can be reproduced in several forms of secondary hypertension - including Goldblatt models and mineralocorticoid excess syndromes.

The hypothesis should identify the mechanism by which a kidney from a genetic hypertensive model can induce hypertension when transplanted into a normal animal [6]. It also must unravel the unique virtue of a normal kidney to reverse hypertension when transplanted into appropriate models of genetic, as well as, Goldblatt hypertension. The hypothesis presented below achieves all that.

\section{Enunciation of the Hypothesis}

The EGFR system is unique among the PGF's in that there exists a potent functional antagonism, during health and disease, between the receptor EGFR and its principal, albeitnotthe sole, agonist - the growth factor EGF. Accordingly, HCVRD can be initiated along two major pathways, which later converge to produce the same result.

In pathway one HCVRD is initiated by increased expression of EGFR in renal tissue. Increased EGFR expression in the kidney (with intact neural and blood supply) is mandatory to start the process; other cardiovascular tissues are influenced secondarily. EGFR when over expressed exerts "agonist independent actions" [7] in which EGFR can lend its tyrosine kinase activity to structurally different receptors, prominently to G protein coupled (GPC) receptors which importantly include angiotensin one receptor (AT1r). EGFR and AT1r also promote mineralocorticoid receptor (MR) to channel all actions of aldosterone (for contrast see below). In order to initiate HCVRD, EGFR excess must overcome the physiological antagonistic and protective actions of EGF.

Increased renal EGFR expression has been documented in the adult spontaneously hypertensive rat (SHR) compared to Wistar-Kyoto (WKY) rats [8]. There is a failure to suppress the normally elevated levels of EGFR observed in all young animals as the SHR grows into adulthood, concomitant with the development of hypertension. Increased renal EGFR mediates the development of hypertension in adult animals of other models of genetic hypertension, including the salt sensitive Dahl strain [9].

Recent reports of beneficial effects of renal sympathetic denervation in treatment of resistant hypertension provide a rationale to propose that renal sympathetic nerve activity is involved in the maintenance of increased renal EGFR expression. It is further proposed that renal denervation should have beneficial effects on cardiac hypertrophy and cardiac failure associated with hypertension, and that this beneficial effect would be mediated by decreased EGFR expression. It is proposed that human hypertension development follows this pathway. This genetic tendency to maintain elevated renal EGFR expression levels can be amplified by other postnatal aberrations of growth and development (see below). Mineralocorticoid and catecholamine excess models of secondary hypertension also utilize this pathway. Both are known to stimulate renal EGFR expression [10].

The second pathway to start the HCVRD continuum is initiated by a primary decline of the EGF supply released from the kidney, resulting in the loss of the physiological function to maintain salt and water balance, as well as the loss of an array of protective mechanisms normally mediated by EGF (see below). Loss of EGF actions leads to functional excess of EGFR actions. The speed and severity of hypertension development in this pathway is dependent on the quantitative loss of EGF (one kidney vs. both kidneys). Hypertension development and actions of EGFR excess take somewhat longer in the presence of an unclipped kidney. Unilateral loss of renal EGF however is not innocuous. Collecting duct renin is up regulated in both kidneys of $2 \mathrm{~K}-1 \mathrm{C}$ Goldblatt rats, independently of blood pressure levels, resulting in increased sodium reabsorption from the collecting duct 
[11]. It is proposed that this hypertensinogenic effect is mediated by a decline in the normal endocrine action of EGF to inhibit renin as well as to inhibit sodium reabsorption locally into the collecting duct (see below). Furthermore the long term safety of unilateral nephrectomy in normal animals has been questioned [12]. Uninephrectomized rats, long term, develop increased blood pressure, creatinine, and evidence for proteinuria, salt sensitivity, and signs of renal injury [13]. All these effects are explained by a decline in EGF and increase in EGFR actions.

Renal EGF is released in response to adequate renal perfusion pressure and optimal interstitial tissue compliance (discussed below). This pathway to initiate HCVRD is used by all Goldblatt models (decline in renal perfusion pressure), excess salt loading models (salt suppresses EGF) and by experimental conditions such as renal decapsulation and wrapping the kidney in cellophane (which interferes with tissue compliance).

The two pathways converge to produce the combined effects of EGFR excess and deficiency of EGF. This convergence by itself does not result in systo-diastolic hypertension, but initiates a syndrome of "prehypertension" causing alterations in cardiovascular-renal structure and metabolic deviations. The development of systolic or diastolic hypertension is the next step (described later).

The demarcation between prehypertension and its progression is not always clear cut, but is treated as such for the purpose of description. The structural changes in prehypertension - such as stiffening and thickening of large arteries, including coronary vessels, vasa recta and arcuate arteries in the kidney and pancreatic vessels, as well as the initial cardiac stiffness and hypertrophy, all represent the combined effects of a decline in EGF's normal function of maintaining tissue compliance (see below) and EGFR's stimulation of transforming growth factor beta (TGF- $\beta 1$ ) and fibroblast growth factor. EGFR is strongly mitogenic for both, a process normally inhibited by EGF. Metabolic deviations in prehypertension also result from the combined actions of EGFR coupled with a deficiency of EFG as described later.

The critical role of mechanotransduction of signals in health and disease has not been well recognized. Reference made here is confined to the cardiovascular-renal tissues.

\section{Under Physiological Conditions}

In the heart, cardiac contraction is regulated on a subsecond scale in response to changes in filling pressure (Starlings Law). The present hypothesis proposes that a similar major principal or law of renal physiology has been missed, and hitherto unidentified. In the kidney, a moment to moment control of sodium and water excretion is exerted by EGF released from its precursor Pre-Pro EGF, in response to variations in the renal interstitial pressure. This mechanism of EGF release, elaborated below, constitutes the basis of "Pressure Natriuresis" which has hitherto defied mechanistic explanation. Renal perfusion pressure has long been quantitatively linked to the level of sodium excretion [14]. Guyton's principal of Primacy of the Kidney in control of sodium excretion, volume, and hence blood pressure, is based on operative pressure natriuresis [4]. And the primacy of the kidney in this regard is explained by the fact that the kidney is the sole source of EGF available for endocrine function. A moment to moment relationship between systemic arterial pressure and renal interstitial hydrostatic pressure to influence sodium excretion has recently been described [15]. The characteristics described of their relationship and their essential independence from autonomic nervous system and renin angiotensin system support the proposal that the mechanism is operated through mechanotransduction of signals - in this case the release of renal EGF.

The molecular mechanisms of mechanotransduction in the kidney are not well understood. Whereas in the heart the contractile proteins respond to the mechanical load by strengthening the contractility of the muscle, in the kidney tissues, application of mechanical pressure leads to unfolding of proteins and reorientation of molecules to favour and promote critical enzymatic reactions. Such a mechanism for mechanotransduction in principal has been proposed [16].

Changes in the conformation of mechanosensitive proteins, such as integrins and cadherins, are the routinely observed effects of mechanical force.

Global force applied to tissues such as renal perfusion pressure and renal interstitial tissue pressure can be transmitted at the cellular level to alter protein conformation to induce changes in specific enzymatic activity [16].

The present hypothesis further proposes that optimal tissue compliance is necessary for the mechanotransduction of signals. In the kidney, an encapsulated organ in direct line of the transmission of aortic pressure, a concept of optimal turgidity and distensibility is introduced as a prerequisite to the proper transmission of renal perfusion pressure to the renal interstitial pressure, and hence the mechanotransduction of signals.

Following a long line of investigations Floyer et al. concluded that an unidentified substance released from the kidney maintains normal tissue compliance in renal as well as extra renal tissues [17]. The present hypothesis proposes that this substance is EGF. It further confirms the thesis of primacy of the kidney in the maintenance of normotension and production of hypertension. The rapid reversal of hypertension on declipping a Goldblatt kidney (about 100 minutes) is accounted by EGF normalizing tissue compliance. The accompanying hormonal changes and salt and water excretion have a longer time course [18]. As eluded to earlier, interference with EGF release is the mechanism of hypertension due to renal wrapping and decapsulation. The same logic applies to the genesis of hypertension associated with renal parenchymal disease, renal tumors and renal stones.

It is proposed that an unidentified enzymatic reaction (perhaps an arginase) operates in response to mechanotransduction to cleave EGF from its precursor. In addition, other significant enzymes such as aminopeptidases and carboxypeptidases are released physiologically in response to optimal renal interstitial pressure and thus compliment the normal protective mechanisms associated with EGF release. Aminopeptidase generates angiotensin 2-8, heptapeptide and the mono-carboxypeptidase produces angiotensin 1-7, heptapeptide. The protective cardiovascular-renal effects of these heptapeptides have been extensively described in recent literature.

\section{Mechanotransduction under conditions of EGFR Excess}

The state of primary excess of EGFR (eg: Prehypertension) has the effect of antagonizing and weakening the normal functions supported by mechanotransduction, such as the Starling Principle in the heart and the release of EGF and EGF mediated functions in the kidney, alluded to earlier. Growth factors have a significant influence on the dispersal of specialized adhesive structures; the clustering of which is normally regulated by GTP-binding protein RhoA [19]. Other members of the Rho family such as Rac and Cdc42 also participate but 
their precise role is less clear. They are more involved in the dispersal of adhesive complexes and their actions are in general opposite to Rho $\mathrm{A}$, and they are stimulated by growth factors such as EGFR, PDGF and Insulin. Growth factors thus weaken the strength of positive reinforcement of adhesive structures which normally occurs with the application of mechanical force.

Furthermore, growth factors have a prominent role in the remodelling of cardiovascular-renal tissues. The nature and character of remodelling is critical to the development of hypertension.

\section{Remodelling of Cardiovascular Renal Tissues}

The old controversy continues, whether structural changes are the result of hypertension or its cause. Elegant descriptions are presented of tissue remodelling caused by increased blood pressure and altered blood flow in hypertension [20]. The possibility that structural changes may contribute to the genesis of hypertension has been considered, but no schema has been offered. The hypothesis proposes that initial cardiovascular structural changes develop, as described below, independent of blood pressure elevations, and are indeed the cause of hypertension. Once hypertension is established additional structural changes secondary to elevated blood pressure develop as part of the continuing target organ damage.

The initial phase 1 of remodelling, which accompanies the stage of prehypertension, is caused by EGFR excess coupled with EGF deficiency including nitric oxide (NO) synthesis and is independent of blood pressure levels. EGFR stimulates TGF- $\beta 1$ and Fibroblast growth factor to produce structural changes in connective and interstitial tissues.

It is the second phase of cardiovascular-renal remodelling described below that is the essential precursor of hypertension development. The critical step is the alterations in "mechanosensitivity" in the remodelling tissues such that the application of mechanical force is now linked to local EGFR transactivation. Essential mediators of this step are the matrix metalloproteinases (MMP) (see below). Focal adhesion kinase (FAK) and non-receptor tyrosine kinase (Src) have also been implicated in the adhesion mediated mechanosensitivity $[2,22]$ and both enzymes are also known to be early initiators of EGFR transactivation $[22,23]$. Also, generation of heparin binding EGF (HBEGF), through MMP action, causing EGFR transactivation has been shown to be essential for the development of cardiac hypertrophy [24]. MMP action has thus, an essential role in causing alterations in mechanosensitivity in remodelling tissues. MMP-2 mediates the process in the vascular tissues (including renal) and MMP-7 with alpha converting enzyme (TACE) mediates cardiac hypertrophy and also stimulates MMP-2 [25,26].

In MMP-2 knockout animals, hypertension does not develop. The absence of MMP-7 prevents cardiac hypertrophy as well as hypertension. Accordingly, at this stage genesis of cardiac hypertrophy is independent of, albeit in parallel with, hypertension. This fact provides an explanation for the observations that the young SHR may show evidence of cardiac hypertrophy before clear evidence of elevated blood pressure. But the appearance time of the two comorbidities is usually so close in experimental models, that it is difficult to exclude the primacy of blood pressure elevation, which once established, is the causal factor for the progression of cardiac hypertrophy. However, the requirement of two different MMP's supports the notion that the nature of tissue remodelling producing changes in mechanosensitivity is likely to be somewhat different in the heart versus the blood vessels.
The importance of this proposal relates to the development of the design of future therapeutic agents for hypertension and heart failure.

\section{Proposed Schema for the Progression of Prehypertension to Systolo-Diastolic Hypertension}

Changes in mechanosensitivity of remodelling tissue allow quantitative linking of mechanotransduction to EGFR transactivation at borderline blood pressure levels of prehypertension.

EGFR transactivation promotes the cardiovascular-renal action of several G-protein coupled receptor agonists such as Angiotensin (AT1r), endothelin I, and sympathetic vasopressors to initiate blood pressure elevation.

The process lends to positive feedback reinforcement (Folkow) and elevation of blood pressure is fuelled by increasing mechanotransduction as well as EGFR transactivation.

Accordingly with progression of CVRD the level of blood pressure and accompanying EGFR transactivation are the principal causative factors for target organ damage [27].

The therapeutic implications of these considerations are discussed below.

\section{Intensive Targeted Treatment of Prehypertension - A Road to Primary Prevention of CVRD}

It is proposed that prehypertension should be vigorously treated to inhibit further progression of the disease. Clinical trials should be conducted to prove the point. In keeping with the present hypothesis, definitive preventive therapy at this stage will require effective inhibition of EGFR actions and EGFR expression, as well as additional supply of EGF and promotion of its protective effects. Antagonists and inhibitors of EGFR have been synthesized for use in the treatment of malignant tumors. Toxicity of these agents, however, is considerable and has not been critically examined for use in non-cancerous proliferative disorders. Development of less toxic analogues now has a strong rationale. Inhibition of EGFR by itself is expected to increase the opposite effects of EGF. Additional therapeutic measures to be examined are: a) to stimulate the endogenous release of renal EGF and b) the feasibility of providing exogenous synthetic EGF in a form suitable for endocrine action.

In addition the following two processes crucial to the development of hypertension should be targeted by future therapeutic regimens:

A critical role for specific MMP's has been described above. Evidence is available on certain factors (other than long term EGFR excess) that mediate stimulation of MMP's: Aldosterone stimulates production of MMP's in the cardiac muscle [28]. The actions of MMP-7 in promoting cardiovascular fibrosis are identical with EGFR excess. Stimulation of MMP2 has been linked to actions of angiotensin through AT1r and a lack of AT2 [29].

Accordingly a trial of aldosterone antagonists combined with angiotensin antagonists for vigorous therapy of prehypertension is recommended. The object of such therapy is not to lower blood pressure levels per se but to retard the progression of hypertension. Although, a narrowing pulse pressure is likely to have a salutary effect of reducing the remodelling stimulus in the cardiovascular tissues.

The second crucial process to be therapeutically targeted is the EGFR transactivation in the local tissues. In addition to the use of 
EGFR antagonists, the enzymes that initiate EGFR transactivation (alluded to above) FAK and Src should be targeted.

\section{Implications on Therapy of Established Hypertension}

A debate in recent years has continued whether the benefits of antihypertensive treatment depend upon a selection of specific drugs, old vs. new, or do the benefits depend largely upon the effective lowering of blood pressure by any antihypertensive regimen [30]. The hypothesis articulated above supports the latter. Blood pressure lowering is the paramount requisite for lowering of the long-term target organ damage. A reduction of mechanical pressure forces, achieved by any effective agent, leads to reduction in mechanotransduction of signals that initiate EGFR transactivation and the accompanying remodelling of the tissues to alter their mechanosensitivity (see above).

This statement, however, does not take into consideration the longterm negative side effects of particular drugs or the special benefits anticipated with the use of certain agents, such as antagonists of angiotensin and aldosterone as alluded to above. Multiple clinical trials in recent years have established that effective antihypertensive treatment of moderate to severe hypertension significantly retards the long-term target organ damage and the progression of HCVRD. It is also established that the benefits in this regard are never absolute and are, at best, partial. The present hypothesis submits that the use of appropriate EGFR antagonists coupled with EGF protagonists can achieve a goal of closer to "curative" treatment. These agents should also prove effective in resistant hypertension, defined as being unresponsive to combined therapy with maximal doses of current antihypertensive drugs [31].

\section{Cardiovascular-Renal Protective Actions of EGF opposing EGFR}

There is a strong teleological rational for an inbuilt system to antagonize and limit the growth potential of EGFR after its mission of early growth in the organism is completed. The rationale remains valid in the adult animal because EGFR retains the ability to exert agonist independent actions [7] when transactivated, most importantly, by Gprotein coupled receptors such as AT1r.

A potent physiological protective system antagonist to EGFR is provided by it agonist EGF. The system has remained unidentified and constitutes the central theme of the present hypothesis. The system is engineered through tailor made molecules and a unique mode of rapid and low intensity (RapLo) contact of EGF to its binding site as described below. It is important to emphasize that the RapLo design of EGF binding is not easily duplicated in vitro or in vivo experimental studies on EGF which as a result do not distinguish direct actions of EGF from those mediated through EGFR [32].

EGF, a single polypeptide of fifty three residues, structurally stable, and resistant to proteolysis, is suitable for endocrine action. It is excreted unchanged in the urine (radioimmunoassay) and the excreted amount grossly reflects active EGF available to the tissues. Urinary EGF is higher in children than the adult, declines further in the elderly, is higher in women than in men, and higher in Caucasians than African American [33,34]. Six disulphide bonds (cysteine residues) represent a highly conserved characteristic of the molecule which is crucial to its anchoring to the membrane domain and binding to the extracellular domain (ECD) of EGFR.
The EGF molecule is synthesized as a large precursor in most tissues, as Pre-ProEGF (1200 residues) and is abundantly present in the convoluted portion of distal nephron ( $10 \%$ of total cell protein) as well as in the thick ascending limb of Loop of Henle [35]. The precursor is an $\mathrm{N}$-glycosylated membrane protein containing several EGF like sequences with the mature EGF molecule at the C-terminal flanked by arginine-asparagine at its $\mathrm{C}$-terminus and by argininehistidine at the $\mathrm{N}$-terminal end. The mechanism of EGF release has been described earlier. It was proposed that the prevailing level of the interstitial pressure in the renal tissues mechanotransduces a proportional amount of arginine specific endopeptidase. The precursor molecule is otherwise resistant to proteolysis, with the potential of being a soluble protein transferable from kidney to other tissues and may act as a transient receptor for AT2r (see below).

\section{Extracellular Domain (ECD) of EGFR}

ECD exerts a potent inhibitory action on EGFR activity. Deletion of ECD results in constitutive activation of receptor kinase, independent of agonist binding [36]. ECD as the N-terminal of EGFR consists of 671 amino acids, containing 51 cysteine residues which constitute $10 \%$ of the total mass. The glycosylated portion of the molecule, at 11 asparagine residues, amounts to $40 \%$ of the total mass. These structural features confer a high degree of thermodynamic stability and resistance to proteolysis, which if cleaved (mechanotransduction) at the transmembrane segment, has the potential of acting as a "serum receptor".

The cysteine content is localized in two regions of ECD which are folded around an area in-between the folds, juxtaposed to a single membrane spanning hydrophobic sequence in the entire EGF molecule. This design favors the rapid ligand binding at low density (Rap Lo), and is responsible for the fact that one molecule of EGF is capable of responding only once to its ligand [37]. This is in contrast to the seven transmembrane GPCR's, including AT1r.

It has been recognized that the intracellular third loop domain of Angiotensin receptors has an important role in mediating signal transduction and cellular function [38], and that the amino acid sequence of the domain is significantly different in AT1r vs. AT2r [39]. In the present context, however, there is another area showing a striking structural difference between the molecules of AT1r and AT2r - the carboxyl terminal tail [40], which mediates their differing cross talk and association with other receptors. In AT1r the C-terminal structure, including a YiiP sequence, provides mechanisms for signal transduction leading to the transactivation of EGFR [40]. In sharp contrast, AT2r has five consensus sites for $\mathrm{N}$-glycosylation and 14 conserved cysteine residues. It is proposed that these structural features in the AT2r molecule dictate its association with Pre-Pro EGF and EGF, as well as the ECD of EGFR.

\section{Receptor Independent Actions of EGF}

Agonist EGF regulates the expression and activity of EGFR via the mode of its binding to the ECD of the receptor. The effects of binding are dependent on concentration and the time of exposure [41]. EGF $\left(10^{\wedge} 10-10^{\wedge} 11 \mathrm{~mol} / \mathrm{L}\right)$ was shown to down regulate EGFR protein expression in cell cultures. Higher concentrations of EGF $\left(10^{\wedge} 7\right.$ to $10^{\wedge} 8 \mathrm{~mol} / \mathrm{L}$ ) increased EGFR expression, and prolonged exposure to EGF was required to stimulate proliferation. For a cell to commit to mitogenesis, presence of EGF is needed for longer than 6 hours [42]. 
Accordingly, it is proposed that the Rap Lo mode of binding is the salient physiological mechanism employed by EGF to antagonize and inhibit EGFR actions and to exert its anti-hypertensive, antiproliferative and anti-atherogenic effects. Under physiologic condition RapLo binding of EGF blocks the mitogenic signals from extracellularly regulated kinases (ERK $1 / 2$ ) to MAPK pathway by inhibiting the activation of an essential intermediate step, the phosphorylation of MEK (also called MAPK kinase kinase) which is mediated through Raf proteins. Activation of Raf is inhibited by cAMP-dependent protein kinase which is stimulated by RapLo EGF binding as well as by AT2r, [43] and Rap Lo NG Aldo receptor (defined below). With longer term binding at higher concentrations, EGF signalling pathway can proceed from ERK $1 / 2$ onward to stimulate mitogen activated protein kinase (MAPK) pathways and also stimulate the latent transcription factors.

It is proposed that one of the most important roles of RapLo EGF binding is to induce the local expression of two important receptors which mediate the "receptor independent actions" of EGF under physiological conditions. The two receptors, as shown in Fig. I, are AT2r and a receptor for non-genomic actions of aldosterone with RapLo characteristics similar to EGF termed as "RapLo NG Aldo" (Figure 1).

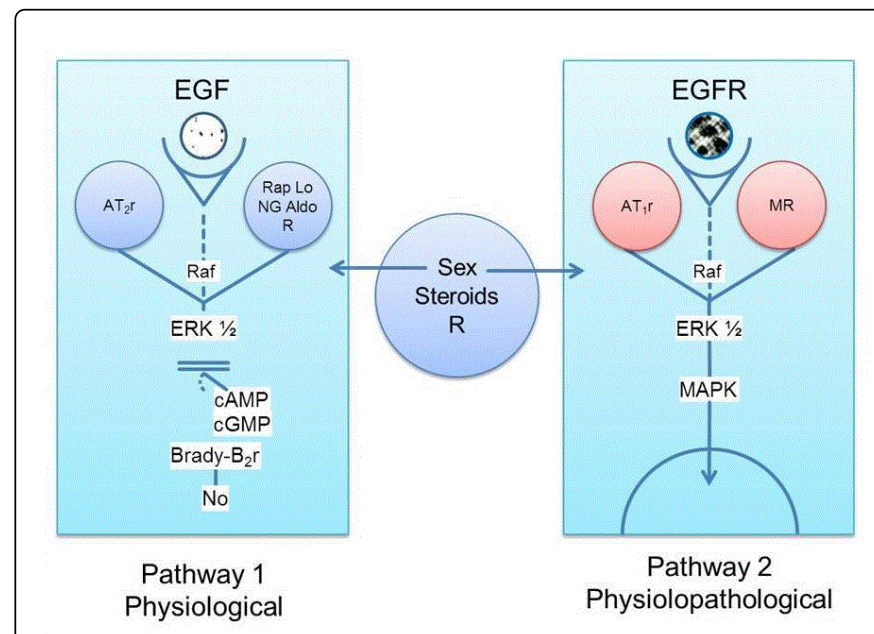

Figure 1: Simplified outline of principal signal transduction for EGF-EGFR.

In Pathway 1: Rapid binding of EGF at low concentrations (RapLo) is the physiological mechanism in which signal transduction of EGF, AT2r and membrane receptor for aldosterone is dominant and signaling thru EGFR is minimized. In Pathway 2: The signal transduction of Pathway 1 is inhibited and EGFR, AT1r and MR directly connect to the mitogenic pathway through MAPK system.

Inhibition of these two receptors is essential to allow EGFR to exert pathological actions, as will be discussed below.

Functional cross talk between Ang II receptors and EGFR is well documented [44].

AT1r activity stimulates signal transduction directly leading to mitogenic (MAPK) pathways, but concomitant stimulation of AT2r inhibits transduction beyond ERK 1/2 [44]. Mechanisms of antagonistic interaction between AT1r and AT2r have been described in detail [43, 45]. Regulation of AT2r expression in tissues, however, is not fully understood. Several growth factors have been shown to modulate its activity [46]. It is proposed that Rap Lo binding of EGF is the principal regulator of the local tissue expression of AT2r, which mediates many of its anti EGFR actions. Sodium depletion has been shown to stimulate AT2r expression [47] in the kidney. It is proposed that the effect is mediated through the influence of sodium balance on EGF activity - sodium loading suppresses and sodium depletion elevates EGF levels (see below). Also consistent with the effects of RapLo binding of EGF pathways are the observations that infusions of low dose angiotensin II stimulate AT2r to decrease arterial pressure in normal animals. The effect is expressed and enhanced in the presence of estrogens and is opposed by androgens [48].

The proposal of a separate receptor for the rapid non-genomic actions of aldosterone as shown in Fig. I (RapLo NG Aldo), impacts upon the unresolved issue of how to explain the dual nature of aldosterone actions (salutary and deleterious). The topic has been actively debated in recent years and remains conflicting and inconclusive. Two major unanswered questions remain:

The identity and functional characteristics of aldosterone receptor or receptors.

The mechanisms which determine whether aldosterone receptor binding results in salutary or deleterious actions on target tissues.

The existence of a "non-classical" membrane receptor for thenongenomic actions of aldosterone separate from the classical mineralocorticoid receptor (MR) has been postulated [49], but none has been identified or characterized. On the other hand attempts made to explain all actions of aldosterone through its binding to MR have not been convincing [50,51]. Before it can be proposed how the present hypothesis reconciles the unresolved issues, it is necessary to delineate the two different pathways which EGF binding to ECD of EGFR can generate.

\section{Pathway 1 (Figure I) Physiological}

RapLo EGF binding $\rightarrow$ AT2r + RapLo NG Aldo R $\rightarrow$ ERK $1 / 2 \rightarrow$ Block

Thus, under most physiological conditions, a potentially mitogenic signal (Pathway 2) is blocked. In Pathway, the extracellularly regulated kinases (ERK 1/2) do not link with MAPK pathway.

In addition there are other significant sites at which Pathway 1 exerts inhibitory influence on Pathway 2.

The extracellular signal in both pathways (EGF binding) leads to the activation of the receptor tyrosine kinase (RTK) of EGFR. The next first link on the cytoplasmic side of the cell membrane in both pathways is the activation of non-receptor Tyrosine Kinase (NRTK) and Src is the prototype. The activity of Src is regulated positively by autophosphorylation at tyrosine 416 in the catalytic domain, and negatively by phosphorylation at tyrosine 527 in the C-terminal via Cterminal Src kinase. Src can be activated also by dephosphorylation at the inhibitory site 527.

Also, the SH2 and SH3 domains in Src structure regulate its activity. $\mathrm{SH} 2$ domain can increase Src activity by binding to phosphotyrosine 527 , and thus removing the negative regulatory influence. Significant increase in Src activity (AT1r mediated) occurs in Pathway 2 [52]. Conversely, Pathway 1potentiates the negative influence of $\mathrm{SH} 3$ domain in Src activity. The function of Src in the mitogenic pathway is to link the signals from RTK's to Ras proteins. NRTK's also serve to link RTK's to the metabolism of phosphatidylinositides. Ras proteins 
include the large groups of guanine nucleotide binding proteins ( $G$ proteins) that mediate coupling of cell surface hormonal receptors to their intracellular effectors. RTK's and GPCR's are linked by common activation of the same second messenger systems.

The link between the actions of Ras and GPCR's is of major pathophysiological importance as a gateway for transactivation of EGFR by GPCR's (characteristically seven transmembrane domains), importantly including angiotensin, but also serotonin, adrenogenic receptors, endothelin, and muscarinic acetyl choline receptors. As discussed below, at this stepEGFR transactivation is facilitated in Pathway 2 and is inhibited in Pathway 1. Ras proteins are inactivated (Ras to GPD) via GTPase activating proteins (GAP) which contain $\mathrm{SH} 2$ and $\mathrm{SH} 3$ domains. These bind to phosphotyrosine and thus act as negative regulators of Ras activity. On the other hand, activation of Ras to GTP is mediated by guanine nucleotide exchange factors (GEF's) which function as a positive control.

A critical activator of Ras (SOS, a GEF) requires an adapter link (Grb2) for its action. Grb2 itself contains SH2 and SH3 domains and thus is subject to negative regulation by EGF (Pathway 1), and positive influence by Pathway 2 (EGFR). There are numerous positive and negative regulators of the actions of EGFR which have been amply documented in the literature [7,23,53-55]. However, a clear recognition of the central issue of crucial importance has been missing which is that the negative regulators are under the direct or indirect influence of EGF dominated Pathway, whereas the EGFR dominated Pathway 2 reinforces the positive influence.

A few examples relevant to the Ras step along the mitogenic pathway are listed below.

Opposing actions of Rab proteins regulate vesicular transport in secretory and endocytic pathways

Opposing actions influence small sized proteins (Rho) which regulate cytoskeleton and participate in mechanotransduction - the important subject discussed previously.

Bradykinin mediates dual actions:

Bradykinin stimulation of PKC can generate the positive signals in Pathway 2, or negative stimuli in Pathway 1 through cAMP.

Bradykinin induces stimulation of $\alpha$ unit of $G$ proteins (hydrolysis of GDP to GTP) which is mediated through GPCR's and EGFR (Pathway 2) but is prevented by EGF in Pathway 1 via cAMP.

Ras proteins provide an essential link between signalling controlled by RTK's to downstream signalling controlled by protein - serine/ threonine kinases (PSTK's) such as Raf proteins and MAPK kinase system. The link to PSTK's is also critical for the operation of several metabolic pathways. PSTK's constitute effectors of metabolic processor initiated by GPCR's and Ras proteins including: cAMP dependent protein kinase (hormonalmetabolism) phosphorylase kinase (conversion of glycogen to glucose), protein kinase $\mathrm{C}$ activated by diacylglycerol (hydrolysis of inositol phospholipids) and calcium calmodulin dependent protein kinases (release of calcium from intracellular stores).

These metabolic processes thus are placed under the opposing influences of EGF vs. EGFR (Pathway 1 vs. Pathway 2).

Ras proteins activate Raf proteins (binding to the inhibitory amino terminal). Activated Raf kinase phosphorylates and activates mitogen activated protein kinase (MARK) a cascade of PSTK's which constitute the next and final mitogenic pathway in the cytoplasm, linking it to the nucleus. The opposing actions of Pathway 1 vs. Pathway 2 continue.

Inhibition of MEK, the link between Raf and MAPK, as well as the blocking of ERK $1 / 2$, have already been described. Both EGF and AT2r can induce this inhibition and cAMP dependent kinase mediates the action.

Pathway 1 can shift MAPK system to increase production of cyclooxygenase COX 2 production, which through prostaglandins and cAMP protein kinase opposes the stimulatory action of Pathway 2 on cell growth.

Induction of C-fos is mediated by dual pathways - MAPK and independently by STAT, which is a protein containing SH2 domains and thus can represent a direct target of RTK of EGFR, bypassing the signalling cascade leading to MAP kinases. EGF in Pathway 1 can induce an inhibitory enzyme to block STAT.

Under certain condition GPCR's have the ability to directly activate MAP kinases (without intermediate steps) through stimulation of protein kinase $C$ or through $\beta \gamma$ subunits of some G-proteins, an action that reinforces Pathway 2. On the other hand phosphorylation by cAMP dependent protein kinase (induced by Pathway 1) opposes this action [7, 23, 53-55].

In Pathway, adrenomedullin, a vasodilator, antihypertensive and natriuretic peptide widely distributed in tissues, including vascular smooth muscle, endothelial cells, and renomedullary interstitial cells, is released [35,56] by EGF receptor action and through mechanotransduction. Adrenomedullin effects are mediated through $G$ protein receptor which produces cAMP and cGMP and nitric oxide.

In Pathway 2, angiotensin II (AT1r) opposes adrenomedullin actions.

\section{Operative Dominance of Pathway 1 vs. 2 Determines the Functional Behaviour of Receptors that Interact with EGF-EGFR}

Several studies have reported (see below) that the receptor types of angiotensin and aldosterone do not always behave in a "predictable" manner under all conditions when expected to transduce salutary vs. deleterious effects. These findings are puzzling only if one assumes that the inherent nature of a receptor alone dictates the result.

The reality, on the other hand, is that the mediation of salutary vs. deleterious effects is entirely dependent upon whether the agonist activated receptor is allowed to employ Pathway, or forced to use Pathway2; whichever is dominant under the conditions. Pathway 1 is operative physiologically but Pathway 2 takes over and is dominant under pathological conditions such as hypertension, heart failure, cardiac hypertrophy, ischemia, and exposure to high salt. Signal switching from one pathway to the other is brought about by second messengers.

Also, there has been misplaced emphasis on the role of the concentrations of the agonists (aldosterone or angiotensin) in mediating the receptor effects. Surely exposure to higher concentrations for longer periods aggravates the target organ damage. However, normal levels of the agonists are entirely capable of transducing deleterious effects through their respective receptors employing Pathway 2. Conversely, the use of receptor antagonists as treatment is beneficial even if agonist levels were normal. 
Thus, it is not the agonist concentration, nor the receptor type above, which determines the deleterious vs. salutary effects; instead, more importantly, it is whether Pathway 1 or 2 is being used for signal transduction.

\section{Angiotensin Receptors}

Angiotensin receptors tend to form physical complexes with EGFR [57]. AT1r forms complexes with the C-terminal part of EGFR [58]. And, in the case of AT2r, it is proposed that structural similarities discussed previously favor a complex formulation with ECD of EGFR and that EGF binding (RapLo) initiates it.

The complex formation activates the receptors and removes specificity requirements for their agonists to transduce downstream signals. In case of AT1r, the transactivation of EGFR and stimulation of MAPK is brought about by a variety of mediators [55,59], independently of a specific agonist. The same is true of AT2r and the production of nitric oxide, the essential end mediator of its effects, does not always require the selective agonist angiotensin II [60]. Instead it can be accomplished by agonists with partial specificity by acting upon different segments of the pathway such as cAMP, cGMP or eNOS expression. The list also includes biologically active fragments of angiotensin and adrenomedullin receptor [56], RapLo Aldo receptor, (see below) and compound 21 [61]. The process is potentiated by association of AT2r (heterodimerization) with bradykinin B2 receptor [62]. As indicated before, AT2r requires an operational Pathway 1 in order to exert its cardio protective and anti AT1r effect.

In experiments in vitro on cardiomyocytes stimulated to hypertrophy [63], the conditions precluded the existence of a functional Pathway, whereas a robust Pathway 2 is dominant. Under these conditions AT2r is not only unable to transduce it's protective and anti AT1r effects but is actually recruited to enhance the effects of the dominant Pathway 2 [63], and the action is agonist independent [64]. According to the above schema, AT2r will be allowed to function only under normal conditions and will be rendered ineffective or even detrimental under pathological conditions when Pathway 2 is dominant. This contention, however, is not supported by facts.

AT2r does exert its effects in early stages of pathological conditions, as long as Pathway 1 is still operative. In later stages when Pathway 2 becomes dominant AT2r recruits the actions of biologically active fragments of angiotensin - principally the two heptapeptides.

Heptapeptide Ang (1-7), sans phenylalanine from octapeptide Ang II, has been shown to be a central component of a powerful "vasoprotective axis" constituted by ACE/2 - Ang (1-7) and mas receptor (65). ACE/2 generating Ang (1-7) is a monopeptidyl carboxy peptidase as opposed to the dipeptidyl carboxy peptidase ACE. The expression of ACE/2 is down regulated in genetic hypertensive models, but is up regulated in heart failure. The mas receptor has varying degrees of affinity for all angiotensin peptides but maximal for Ang (1-7). The "vasoprotective axis" certainly employs the vasoprotective machinery of AT2r including NO production and anti AT1r effects [65, 66].

It is unclear if components of the axis have independent effects [67,68]. Ang (1-7) induces mas receptor internalization [69] and possibly of AT2r along with.

The second heptapeptide, des-aspartyl Ang II (created via an aminopeptidase) Ang (2-8) has been shown to be the predominant agonist for AT2r in mediating the inhibition of sodium reabsorption from the proximal tubule in the kidney [70].

Ang (2-8) heptapeptide compared to octapeptide Ang II is known to be much weaker as a pressor agent, but almost equipotent in releasing aldosterone from adrenal cortical cells.

\section{Aldosterone Receptors}

Since the recognition of the non-genomic actions of aldosterone [49], more questions than answers have arisen about the identity and behaviour of its receptors and the mechanisms of aldosterone actions onnonepithelial tissues. A critical review of the vast and conflicting literature on the subject is far beyond the present scope. Instead the relevant elements of the present hypothesis are enunciated to address the unanswered questions.

\section{The Receptors}

There are two receptors for aldosterone, the classical mineralocorticoid receptor (MR) and the membrane receptor (Rap Lo NG Aldo R) shown in figure 1 . The latter responds only to rapid actions of aldosterone at low concentrations and its actions are characterized as follows:

\section{Not blocked by spironolactone}

Not blocked by inhibitors of protein synthesis

Is present in MR null mice

Is inhibited by blockers of NO synthesis

Rap Lo NG Aldo $\mathrm{R}$ is an integral part of Pathway 1 with other components participating in mediation of its actions, such as to share intracellular actions with EGF (increased $\mathrm{pH}$ and mobilization of $\mathrm{Ca}+$ + ). Both EGF and AT2r share intermediate effectors (cAMP), as well as the final effector of NO production with Rap Lo Aldo R. There are two actions of fundamental importance, however, in which Rap Lo Aldo R takes the lead:

Antagonism of the genomic actions of MR on sodium reabsorption in the kidney [49].

Activation of MR for transmission of the non-genomic actions of aldosterone at concentrations and time of exposure higher than those that can be mediated through Rap Lo Aldo R under the prevailing conditions

This mode of MR activation explains important unanswered questions [50] (see below). Rap Lo NG Aldo R actions are salutary when transmitted through Pathway 1. The membrane receptor, however, can produce deleterious effects under conditions of the dominance of Pathway 2.

In ischemic canine hearts (Pathway 2) rapid non-genomic actions of aldosterone (spironolactone insensitive) were shown to worsen ischemia $[7,72]$. The same pattern of salutary effects through Pathway, and deleterious effects through Pathway 2, holds true for the activated MR [73].

In sodium deficiency, elevated aldosterone mediates vasodilation of renal vessels through MR. Inhibition of vasoconstriction of renal afferent arterials caused by aldosterone is mediated through MR and therefore sensitive to spironolactone [74]. It is in the area of deleterious effects of aldosterone mediated through MR that the 
present hypothesis provides clarification for the following two major unanswered and much debated questions:

\section{Activation of MR by Low Normal doses of aldosterone via Rap Lo NG Aldo R}

$\mathrm{MR}$, having multiple agonist including glucocorticoids, lacks strict specificity for aldosterone and it is the function of Rap Lo NG Also R to provide the specificity and activate MR at low normal levels. This results in target organ damage when mediated through Pathway 2, such as in heart failure and hypertension, as demonstrated by the efficacy of spironolactone treatment in several clinical studies including the randomized Aldactone Evaluation Study [50]. As noted earlier, there has been a misplaced emphasis on the requirement of aldosterone levels to be elevated to cause activation of MR and target organ damage. Higher aldosterone levels do cause greater and more rapid damage, but low normal aldosterone levels cause damage through activated $\mathrm{MR}$, which can occur at lower than normal aldosterone levels in heart failure.

The proposed model of MR activation also gives credence to suggestions of long ago (Genest) that modest but sustained elevations of circulating levels of aldosterone can cause hypertension.

\section{Mechanism of Greater Target Organ Damage in Aldosteronism than in Essential Hypertension}

In a well-controlled study, cardiovascular complication associated with primary aldosteronism was greater than those in essential hypertension [75]. Left ventricular hypertrophy in patients with primary aldosteronism was shown to be disproportionate to the hemodynamic load and level of blood pressure [76]. Possible mechanisms have been discussed without identification of the specific cause [77]. The mediation by EGFR of the cardiovascular damage caused by mineralocorticoidshas been recognized [78-80]. Also renal damage in primary aldosteronism has been well documented to be greater than in essential hypertension [81].

The missing link has been the recognition that aldosterone is known to increase the expression of EGFR [10] which accounts for its disproportionate effects on target organ damage. Furthermore, the same mechanism of aldosterone stimulating EGFR expression is responsible for metabolic dysfunction associated with aldosterone. Plasma aldosterone has been shown to be independently associated with metabolic syndrome [82] and the cause of this association has been hitherto unexplained.

\section{Salt and Aldosterone}

It has been amply demonstrated that aldosterone in the presence of high salt diet leads to cardiovascular [83] and renal damage [84] in patients with hypertension, and that low salt diet is capable of reversing these effects [83-85]. The mechanisms underlying this important observation of fundamental relevance have not been adequately explained.

High salt diet has a powerful inhibitory effect on the function of Pathway 1. High salt diet has been shown to inhibit the expression of AT2r [86] and it is proposed that EGF release from its precursor via mechanotransduction is less efficient in the presence of high salt intake. The inhibition of Pathway 1 leads to the dominance of Pathway 2 (AT1r). Low salt diet, on the other hand, has the opposite effect of stimulating the function of Pathway 1 and to reverse the dominance of
Pathway 2, and hence lower target organ damage, so long as aldosterone is not elevated.

It is recognized that salt and aldosterone act in concert to produce a combined effect on target organ damage $[83,85]$. High salt intake requires elevated aldosterone to produce target organ damage and conversely low salt intake requires aldosterone to be normal for the full expression of its salutary effects. This latter half of the equation has not been adequately emphasized when considering sever degrees of dietary salt restriction in patients with cardiovascular disease. Benefits of sever restriction of dietary salt in these patients are counterbalanced with the effects of low salt on the stimulation of aldosterone levels.

Indeed the existence of an unexplained "J" shaped relationship has been reported between dietary salt intake and the incidence of cardiovascular disease in large population studies [87]. It is proposed that the deleterious effects of elevated aldosterone in response to sever degrees of salt restriction accounts for the observed "J" shaped curve.

\section{Prorenin-Renin Receptors ((P)RR)}

The subject is aptly called a moving target at this time. Recent reviews [88-90] emphasize the gaps in the knowledge, including a definition of physiopathologic significance [91]. Comments here are limited to a brief look at the selected data through the prism of the present hypothesis.

EGF is a potent inhibitor of renin and prorenin [92]. EGF also inhibits the expression of (P)RR as evidenced by its upregulation in the clipped kidney of Goldblatt hypertensive rats given antihypertensive therapy [93]. A lowering of renal perfusion pressure diminishes EGF release and thus decreases the inhibitory influences of EGF on (P)RR expression.

Also AT2r has been shown to inhibit renin biosynthesis [94]. Accordingly it can be proposed that under physiological conditions, Pathway 1 (EGF and AT2r) keeps the interaction of prorenin and renin with (P)RR to a minimum. Conversely, AT1r (Pathway 2) up regulates $(\mathrm{P}) \mathrm{RR}$ expression as observed in stroke prone SHR (89). (P)RR in its soluble form is up regulated in the collecting duct and urine of rats made hypertensive with chronic Ang II administration [95].

Binding of prorenin to (P)RR produces a conformational change, leading to signalling through MAPK and to pathological changes such as glomerulosclerosis [89]. It is proposed EGFR transactivation mediates these changes. A suggestion to the contrary [96] does not rule out the possibility.

Studies on genetically induced elevations of $(\mathrm{P}) \mathrm{RR}[88,89]$ have revealed the existence of a trend showing that higher rates of $(P) R R$ expression are required to produce hypertension which was accompanied with unexplained elevations of plasma aldosterone [89]. Animals with lower levels of (P)RR expression did not develop hypertension but showed evidence of renal damage.

This pattern conforms to the clinical course proposed by the present hypothesis. "Prehypertension" with some target organ damage precedes the development of hypertension which requires structural remodelling of cardiovascular tissues. It is proposed that elevated aldosterone mediates the remodelling of tissues [28]. Recent clinical studies in high risk patients, renin inhibitor therapy was added to complete renin angiotensin blockage and was shown to produce adverse effects [97]. Multiple mechanisms have been discussed that 
may potentially be responsible [97]. It is proposed that elevated aldosterone mediates some of the adverse effects of the renin inhibitor in this setting.

\section{Physiological Role of Pathway 1 to Inhibit Renal Sodium Reabsorption}

Enhanced renal sodium reabsorption is a requirement for the development of hypertension and EGFR transactivation in Pathway 2 mediates the process. Chronic infusions of angiotensin enhance sodium reabsorption in the distal nephron [98]. Aldosterone maintains enhanced reabsorption through its genomic action via MR. Endothelin is known to participate in regulation of salt balance in hypertension [99]. Enhanced AT1r activity in hypertension not only promotes sodium reabsorption through ETA receptors [100] but also alters the action of ETB receptors to cause increased sodium transportation in the proximal renal tubules, whereas ETB receptors normally inhibit renal sodium reabsorption [101]. All of the above actions of Pathway 2 are physiologically antagonized and inhibited by Pathway 1. Although all elements of Pathway 1participate (see below) in this important function, yet EGF takes the lead.

EGF receptor signalling in the kidney has been recognized as a major regulator of electrolyte (including magnesium) homeostasis [102]. It is proposed that this function is performed by the receptor independent actions of EGF (Figure 1). EGF inhibits sodium transport in the cortical collecting ducts. Calcium influx across basolateral membranes and increased free cytosolic $\mathrm{Ca}+$ were deemed to mediate this action [103]. In addition EGF has been known to inhibit amilioride sensitive sodium reabsorption [104] in renal collecting ducts. Also, receptor tyrosine kinases in the distal nephron have been shown to mediate inhibition of epithelial sodium channel by EGF [105].

It has been suggested that rapid non genomic actions of aldosterone (Rap Lo NG Aldo R) potentiate the inhibitory actions of EGF on sodium reabsorption [49] and EGF signalling has been viewed as a negative feedback control of aldosterone induced $\mathrm{Na}+$ reabsorption [106]. The other important component of Pathway, AT2r inhibits $\mathrm{Na}+$ reabsorption in the proximal tubule via mediation of angiotensin III [70]. N-Aspartyl aminopeptidase required to generate angiotensin III may have a mechanism of release in the kidney common with EGF (mechanotransduction) as proposed in a previous section. A recently proposed functional role for ETB receptors in the relationship of renal perfusion pressure and natriuresis [107], brings up the question of cross talk with EGF, especially because both ETB as well as EGF are richly distributed in the thick ascending limb of the loop of Henle and the collecting ducts. ETB receptor function in pressure natriuresis, which is only observed in the presence of high salt, may complement the EGF function described earlier.

Accordingly, EGF, employing multiple mechanisms, plays a dominant role in the complex process of the control of sodium reabsorption in health as well as disease. The dynamics of EGF release from the kidney have not been studied in hypertensive patients during the progression of the disease. It is proposed that EGF release is enhanced in the early stages of hypertension, and declines with its progression. The reason for the decline of EGF release in patients with the moderate to severe hypertension may be the development of cardiovascular renal rigidity with loss of tissue compliance which may interfere with optimal mechanotransduction. Also, the supplies of PrePro EGF may become limiting.
If this pattern of EGF release is confirmed in mild, moderate and severe grades of hypertension it will have profound implication on the classical renin sodium profiling in hypertensive populations.

\section{EGF and Renin Sodium Profiling}

Renin sodium profiling of hypertensive patients (Laragh), classified groups with low, normal and high plasma renin and causally related the same to high, normal and low urinary sodium excretion respectively. It has been somewhat of an enigma how the measured plasma renin which, although does not faithfully reflect the circulating levels of the effector compound angiotensin much less the production of angiotensin at the tissue level, can display a discernible inverse relationship with urinary sodium excretion and more surprisingly with the incidence of events resulting from target organ damage in hypertensive population [108]. It is proposed that several dominant properties of EGF are responsible for the observed relationships which, hitherto, have been spuriously attributed to measured plasma renin. As noted previously, EGF is a potent inhibitor of renin release [92] and a potent inhibitor of renal sodium reabsorption. Thus the measured renin levels in the groups actually inversely represent EGF levels (Figure 2). In the low renin group the suppressed renin is due to higher levels of EGF (preserved response to higher renal perfusion pressure) which also accounts for greater inhibition of sodium reabsorption and the observed rates of higher urinary sodium excretion. More importantly, the higher levels of EGF account for the lower incidence of target organ damage as articulated in this hypothesis.

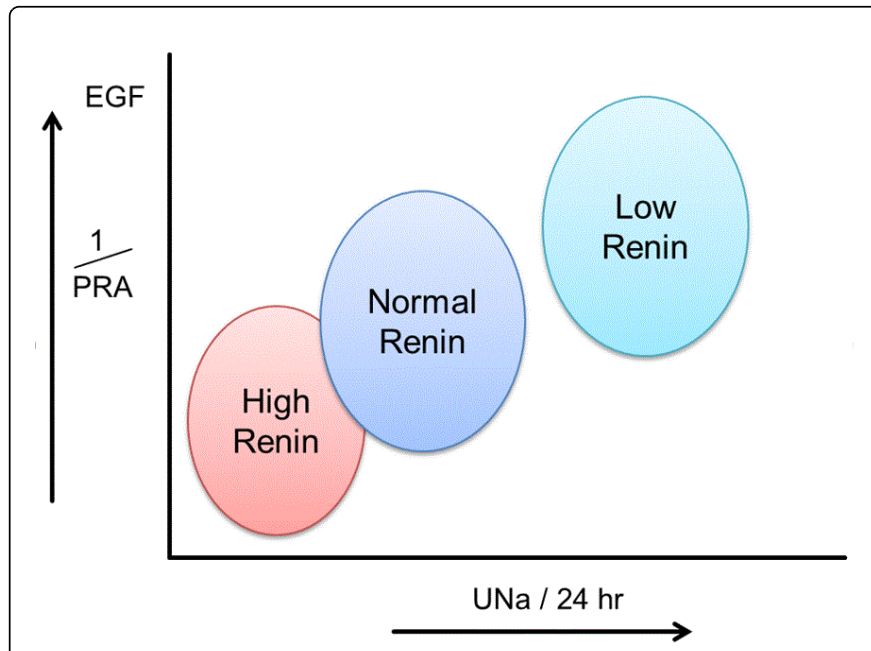

Figure 2: The reported relationship of urinary sodium excretion with plasma renin activity (shown as a schematic) is mediated by the level of suppressive action of EGF on Renin. Urinary sodium corresponds to the inhibitory action of EGF on sodium reabsorption.

\section{EGF Actions Explain Relationships between Renin Profiling, Calcium Metabolism, and Sodium Sensitivity and Resistance in Hypertensive Subjects}

In providing a rationale for dietary calcium and magnesium therapy for patients with hypertension, several parameters related to calcium metabolism were correlated with low, normal and high renin 
Page 10 of 18

subgroups of hypertensive patients [109]. Serum ionized calcium and calcitonin levels showed a direct relationship by being low in the low renin group. On the other hand, Vitamin D, parathormone and serum magnesium levels exhibited an inverse correlation, being higher in the low renin group. Therapy with calcium channel blockers and short term oral calcium supplements were shown to be more effective in hypertensive subjects with low renin compared with those with high renin. Strong calcium-sodium interactions were demonstrated in salt sensitive hypertensive subjects. Increased dietary salt reduced serum calcium and elevated blood pressure. Oral calcium supplementation blunted salt induced hypertension [109]. It is proposed that EGF actions listed below constitute the basis for the relationships described above.

EGF inhibits phosphate uptake as well as $\mathrm{Na}++$ /phosphate cotransporter in the renal proximal tubule and this inhibition is dose dependent [110]. Accordingly the inhibition is more potent in the low renin group of hypertensive patients in whom EGF levels are higher.

As previously noted, EGF inhibition of sodium transport in renal cortical collecting ducts [103] is mediated by calcium influx across basolateral membranes resulting in increased cytosolic free $\mathrm{Ca}++$. EGF activates $\mathrm{Ca}++$ ionic channels resulting in increased $\mathrm{Ca}++$ influx and also activates $\mathrm{Ca}++$ dependent $\mathrm{K}+$ channels [111].

Along with increased $\mathrm{Ca}++$ influx, EGF stimulates $\mathrm{Na}+\mathrm{H}+$ antiport activity leading to alkalization of the cell [112].

EGF is known to regulate magnesium homeostasis [103]. Serum magnesium levels are higher in the low renin group of hypertensives [109].

The present hypothesis proposes that available levels of EGF determine the patterns of salt sensitivity and resistance in hypertensive as well as in normal subjects.

When EGF levels are low, such as in high renin groups of hypertensives or low volume and sodium depleted normal subjects (low renal perfusion pressure), the given sodium loads are not well excreted and blood pressure rises. Conversely in low renin group of hypertensive subjects with higher levels of EGF or volume expanded normal subjects (with optimal renal profusion pressure) sodium loads are efficiently excreted and blood pressure is unchanged or lower.

The concept of sensitivity or resistance to salt derived its legitimacy from inbred genetic models of Dahl's salt sensitive or resistant strains. The hope, however, that a genetic tendency on a similar basis might reflect two distinct populations in essential hypertensive subjects has not been realized. Nor has the concept been helpful in identifying subjects for any specific therapy including salt restriction. The use of salt restriction or diuretics has not been particularly helpful in identifying salt sensitive subjects. However, the characteristics of suppressed renin responsiveness to these measures have been associated, with some consistency, with salt sensitivity (a better blood pressure lowering response in black or older subjects). This observation is consistent with the hypothesis proposing that the diminished renin responsiveness is a feature of EGF action. Indeed it is proposed that the genetic basis for the Dahl's inbred salt sensitive and resistant strain lies in a deficiency of the synthesis or release of EGF.

\section{Cause and Consequence of Increased EGFR Expression in the Kidney}

Enunciated earlier as the hypothesis, Hypertensive Cardiovascular Renal Disease continuum is caused by increased renal expression of EGFR. The cause of increased renal EGFR can be classified into three categories (Figure 3):

Genetic

Epigenetic

Non-genetic

In the normal adult animal, EGF receptors are found in glomeruli, in the basement membranes of proximal tubule, in the collecting duct and in the medullary interstitial cells of the kidney [35]. The distribution of EGFR under condition of increased expression or in hypertensive animals has not been reported.

In genetic as well as epigenetic causes, increased renal EGFR expression represents a failure of the mandatory increased expression during early growth period to downgrade to normal in adulthood, when requirements of growth period are complete. In the non-genetic category, stimulation of EGFR expression is independent of genetic mechanisms but may be amplified because of them.

\section{Increased Renal EGFR Expression as a Genetic Trait}

Since the description of inbred hypertensive strains in the rat $[113,114]$, it has never been identified what trait actually is inbred which later manifests itself as hypertension. The present hypothesis proposes for the first time that the said trait in the SHR is the increased renal EGFR expression continued from infancy to adulthood [8,9]. It is further proposed that the trait is expressed in subjects with essential hypertension as a Gaussian distribution curve (Figure 3), thus conforming to the thesis of Pickering [115,116], and discounts the proposal of a bimodal distribution by Platt [117]. The genetic trait maintains increased EGFR expression through gene amplification.

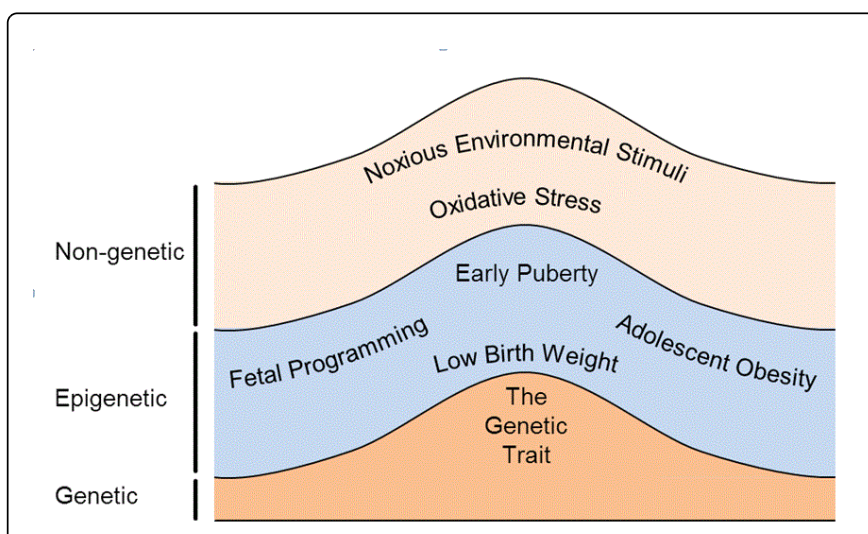

Figure 3: Distribution (schematic) of the genetic, epigenetic and non-genetic hypertensive factors in the general population

\section{Epigenetic - Alterations in Patterns of Growth and Development}

A number of conditions have been identified starting from intrauterine life to adolescence which result in hypertension in later 
life but have in common the propensity to alter the normal pattern of growth and development and place a continued demand, akin to early growth period, on the organism achieving adulthood. Understandably a great deal of attention has been focused on these conditions to discover a connection with causation of hypertension [118,119].

Elegant concepts have been advanced on the role of fetal programming and developmental plasticity to suggest that adverse intrauterine events can alter the subsequent road map of growth and development and cause changes in the kidney (reduced nephron number and fibrosis) that may later result in hypertension [120]. Also, early onset of puberty has been related to the later appearance of hypertension, promoting the concept that the age at puberty may be a marker for growth trajectory [121]. Similarly a low birth weight has been correlated with the subsequent incidence of hypertension $[122,123]$. The data on the subject, however, has been conflicting and it appears the adiposity in the post natal period rather than the weight at birth shows a better correlation with the incidence of hypertension [124-126].

Despite these credible and promising "correlates" of the appearance of hypertension, the cause for the genesis of hypertension has not been revealed. The present hypotheses proposes that all of the "correlates" have one salient feature in common, which is to place a demand for continued growth of the organism reaching adulthood and thus interfere with the downgrading and normalizing renal EGFR expression. It is the continued increased EGFR expression which later results in hypertension. The proposal gets strong support and confirmation from the observations made in large scale studies [127] showing that hypertension in the young has a high incidence of adiposity in the youth and is accompanied by metabolic deviations, as well as in the "prehypertension syndrome", in the same fashion as described earlier for genetic and essential hypertension [127-129]. Again, it is the continued increased expression of EGFR which is responsible for the genesis of metabolic deviations, the prehypertension syndrome, and the later onset of hypertension.

It has been suggested that the above referenced epigenetic factors transmit an intergenerational influence through non-genetic mechanisms of inheritance $[12,130]$. It is likely that the epigenetic category contributes significantly to the incidence of hypertension in modern populations (Figure 3 ).

\section{Non-Genetic Causes}

The non-genetic causes which can stimulate EGFR expression include gamma radiation, osmotic shock, membrane depolarization, and exposure to radical generating agents such as hydrogen peroxide and certain heavy metal ions [7]. Also included in this category are certain cytokines such as growth hormone (acromegaly associated hypertension). The quantitative contribution of these factors to the incidence of hypertension is unknown but appears to be considerable.

\section{A Potential for Primary Prevention Using Early Treatment with ACE Inhibitors}

The general principals of Primary prevention have been discussed earlier. The concept receives strong support from specific examples here. If the young SHR in the prehypertensive stage are treated with ACE inhibitors for an optimal period, the long-term blood pressure remains reduced when the hypertensive phase sets in the adult SHR. And the long-term target organ damage is also reduced in the SHR receiving early treatment. The findings were not reproducible if other blood pressure lowering drugs not related to angiotensin were employed for early treatment as controls [131]. This significant observation failed to receive due recognition because the mode of action of ACE inhibition in the experiment was not fully appreciated. It is proposed that blood pressure lowering effect of ACE inhibition is not relevant (other anti-hypertensive agents do not achieve the same results) and that the salutary effects are entirely due to a reduction of the level of EGFR expression produced by a reduction of the agonist action of angiotensin and AT1r on EGFR transactivation. The proposal is supported by observations showing that treatment with ACE inhibitors or AT1r blockers exhibits anti-growth properties in cancer cells [132] and anti-proliferative efficacy in cancer patients [133]. Some clinical trials were initiated [132].

Considering the high value target of primary prevention, and proven relative lack of toxicity of ACE inhibitors and angiotensin receptor blockers, combined with an acceptable tolerance by a majority of treated subjects, it is mandatory that large scale randomized clinical trials should be organized. In the meantime the following improvements in the design of the said trials should be actively sought:

To devise a quantitative measure to monitor the effects of treatment on EGFR expression levels using samples of blood, serum, urine and skin biopsies.

To design and test new drugs such as:

Analogs of anti-angiotensin agents which lack the blood pressure lowering activity but exhibit enhanced anti-EGFR potency.

Anti-EGFR agents with reduced toxicity than those currently available

A combination therapy with anti-angiotensin and anti-EGFR agents

To refine the clinical parameters of treatment protocol considering the:

Selection of subjects for treatment

Age to start treatment

Length of treatment

\section{Who should be treated}

If effective and well tolerated anti-EGFR agents were available and clinically applicable, and reliable methods existed to monitor EGFR expression during treatment, a case could be made to treat everyone at risk of developing hypertension. And indeed, when increased EGFR expression is fully proven and accepted as the fundamental fault in hypertension the concept of a "vaccine" in childhood will become a valid objective to pursue; which will protect against "excessive" expression of EGFR.

Regarding the selection of subjects for clinical trials, it should be noted that in the genetic and non-genetic categories shown in Figure 3 , the selection from general population of those who may eventually become hypertensive can be subject to error. Features of prehypertension, such as borderline elevation of systolic blood pressure or metabolic deviations, when present, are helpful indicators to identify those who should be treated.

In sharp contrast, the category labelled as "epigenetic" (Figure 3) is eminently suitable for clinical trials on primary prevention of hypertension because a well-defined sample suitable as the target of 
treatment is already available. All of the "epigenetic" markers such as intrauterine events, a low birth weight, childhood obesity and early onset of puberty are indications for early treatment.

\section{Consequences of EGFR Overexpression}

Effects of EGFR overexpression have been studied in relation to cancer but not in the context of non-tumorous proliferative disorders, which the present hypothesis classifies the HCVRD continuum to be. Increased EGFR expression has profound effects on signalling pathways. High receptor density promotes its dimerization, which controls receptor endocytosis [134], which is further regulated by GPCR's [135] prominently via a mutual interaction with AT1r [57].

Increased EGFR expression causes sequestration of ERK's and selective attenuation of specific EGF mediated signal pathways [136, 137]. Most importantly it alters the nature of EGF binding from the normal "Lo Rapid" binding to a higher concentration and prolonged binding mode [138]. These alterations cause fundamental changes in EGF-EGFR function in the context of the hypothesis as follows:

The loss of "Rapid Lo" binding of EGF attenuates Pathway 1 and thus the availability of AT2r and Rap Lo NG Aldo R.

The dominant operative pathway now becomes Pathway 2, in which AT1r and MR take over and mediate the function of angiotensin and aldosterone respectively.

Increased EGFR expression, as previously discussed, initiates the syndrome of "prehypertension".

\section{Prehypertension}

A survey of the vast literature on the subject is outside the present scope. Instead arguments are summarized (with minimum citation of references) to support the thesis that prehypertension and its manifestations owe their genesis entirely to the increased expression of EGFR and consequent decline of EGF function. Levels of concomitant blood pressure and hormones such as angiotensin, aldosterone and catecholamines, at this stage, do not contribute to the genesis of prehypertension. These factors, however, influence the manifestations of prehypertension, but do so by their interaction and effect on increased expression of EGFR (see below). Following are the salient accompaniments of prehypertension syndrome.

\section{Hyperuricemia (HYRU)}

\section{Causation}

Elimination of uric acid and other organic anions require an essential step of basolateral anion uptake in the proximal renal tubule mediated by EGF, which also recruits PGE2 via protein kinase A $[139,140]$. This critical step is countered by EGFR overexpression resulting in compromised elimination of organic anions, including uric acid.

\section{Clinical Correlates}

Uric acid elimination shows a remarkable quantitative relationship with prevailing levels of EGFR activity, thus rendering elevated serum uric acid as a faithful marker of EGFR overactivity and its consequences. Serum uric acid levels are strongly correlated with albuminuria in prehypertensive (non-diabetic) subjects [141]. New onset of hypertension (prospectively in a large population) shows a strong relationship with the development of hypertension, independent of other factors [142].

In established hypertension HYRU is an independent predictor of $\mathrm{LVH}$, carotid abnormalities and other indices of target organ damage and cardiovascular-renal risk and disease [143,144]. The above described strong relationships with HYRU [141-144] have raised the question if uric acid is directly involved in the pathogenesis of hypertension. The present hypothesis provides a clear answer to that question. Uric acid levels are a strong, reliable and independent marker of EGFR over activity. A weaker correlation of serum uric acid with indices of cardiovascular-renal disease, observed in hypertensive women compared with men, is explained by the negative effect of estrogens on EGFR signal transduction [145].

\section{Microalbuminuria (MALB)}

\section{Causation}

It is proposed that an important endocrine function of EGF is to maintain tight junction sealings between epithelial cells along the entire nephron [146]. EGF action controls the amount and distribution of occludins and claudins, by translocating these proteins from cytoplasm to within intercellular contacts [147]. It is proposed that the glomerular membrane requires a higher concentration of EFG to ensure its integrity than the epithelial cells of the nephron. It is proposed that the objective is achieved by the design of macula densa in having the EGF rich distal tubules in close proximity to the glomerulus.

\section{Juxtaglomerular (JG) Apparatus - A Teleological Rational for its Structure}

The old, seemingly attractive concept, proposing that renin secretion from JG cells is regulated by sodium concentration or load in the distal tubule, has never been validated. Indeed it has been disproven, but has survived as conventional wisdom. It has been conclusively shown that JG cells are capable of releasing renin in the absence of sodium delivery to the maculadensa [148]. Multiple factors control renin secretion [149]. The structural closeness of distal tubular cells (lacking basement membranes) with the cells of macula densa, is not a design required for ionic transport, but rather speaks for facilitating the transport of peptides and proteins. It is proposed that the teleological rationale of the design is to provide EGF from the distal tubule to the glomerular membrane in much higher concentrations than available in plasma or glomerular filtrate. Increased EGFR expression opposes this normal function and leads to "leaky" membranes.

\section{Clinical Correlates}

A great deal of investigative effort has been devoted to microalbumin (MALB). Several huge prospective population studies have focused on correlating the course of MALB with concomitant levels of blood pressure, blood sugar, renal function and therapeutic effects of relevant hormone receptor antagonists. Yet the pathogenic cause of MALB has not been revealed. It is submitted that the available data, however, supports the proposed hypothesis that MALB originates as a deficiency of EGF function and later quantitatively promoted by increasing levels of EGFR expression. 
Unlike HYRU, which is a mirror reflection index of EGFR activity, multiple factors overlap the role of EGFR in case of MALB. Nevertheless the progression of MALB closely parallels the course of HYRU [141] and a reduction in MALB parallels a reduction in cardiovascular events in hypertensive patients [150]. MALB (defined as albumin excretion of $>5 \mathrm{ug} / \mathrm{min}$ ) correlates with incidences of new coronary heart disease and death [151]. Genesis of MALB is independent of blood pressure levels and a dissociation between blood pressure reduction and a fall in MALB with treatment has been shown in several studies [152].

Conclusive evidence in favor of increased EGFR activity being the quantitative cause of MALB comes from treatment studies with antagonists of hormone receptors such as angiotensin [153], aldosterone [154] and adrenergic hormones [155]. The resulting reduction in MALB is independent of the blood levels of those hormones or their cellular effects. The hormone receptors (GPCR's) are known to transactivate EGFR and their antagonists suppress EGFR activity. Strong experimental support for the concept has been provided in the case of AT1r. Using antisense oligonucleotides against AT1r, it was demonstrated that a decrease in renal AT1r protein leads to a parallel decrease in MALB, independently of changes in blood pressure and circulating levels of A II [156]. The concept is further supported by an observation that the effects of these diverse hormone receptor antagonists can be additive when used in combination.

Long term sustained glycaemia with increasing levels of blood sugar in hypertensive patients have been linked to the development of MALB [157]. Higher levels of sustained glycaemia have been known to stimulate renal EGFR expression.

\section{Stiffening of Conduit Arteries}

Stiffening of large conduit arteries (partly discussed in a previous section) is the dominant feature of prehypertension, causing significant pathology in multiple organ circulations, and producing its hallmark hemodynamic pattern of a wide pulse pressure and an accelerated pulse wave velocity - features that have been utilized to clinically diagnose the condition.

\section{Causation}

Similar to the other manifestations of prehypertension, the unrecognized cause of arterial stiffening is the blocking of the normal actions of EGF and Pathway 1(Figure 1) and over activity of EGFR and Pathway 2. In normal humans, endothelial function and bioavailability of NO relate directly (independent of other factors) to the range of pulse pressure as well as the pulse wave velocity. Direct measurements of intra- arterial pulse wave velocity confirm that local availability of NO modulates the distensibility of human conduit arteries without alterations in systemic arterial pressure [158].

EGF and Pathway 1 play a vital role in regulating NO bioavailability. NO production is stimulated by cellular actions of EGF through increase in the intracellular $\mathrm{pH}$ via $\mathrm{Na}+\mathrm{H}+$ exchange (discussed previously). NO mediated phosphorylations require the presence of EGF [159]. As discussed earlier, AT2r stimulates phosphorylation of $\mathrm{NO}$ synthesis through Bradykinin B2 receptor pathway and this action requires the presence of EGF to mediate the phosphorylation. The aldosterone membrane receptor (Figure 1) also stimulates NO production mediated thru AT2r.
In addition EGF participates in the maintenance of normal compliance of arterial system thru its action on $\mathrm{Ca}++$ and $\mathrm{K}$ channels [111]. EGFR and Pathway 2 oppose these normal functions, and as stated earlier, stimulate the expression and actions of TGF- $\beta 1$ and fibroblasts.

AT1r in Pathway 2 mediates cardiovascular-renal damage (LVH and MALB) thru stimulation of TGF- $\beta$, which also stimulates collagen type I [160]. Biochemical tissue analysis in myocardial fibrosis revealed collagen type I [161]. Inflammatory changes in cardiovascular tissues, resulting from chronic inhibition of NO synthesis (Pathway 1), are linked to TGF- $\beta 1$ [162]. In later stages, TGF- $\beta 1$ participates in the progression of heart failure [163]. Most significantly, AT1r has been shown to stimulate the expression of TGF- $\beta 1$ (thru upregulation of its receptor subtype endoglin) in the coronary endothelial cells, leading to proliferative changes via MAPK signalling [164].

\section{Clinical Correlates}

In the prehypertensive phase, the above-described changes are independent of blood pressure levels. It is proposed:

The fibrotic stiffening of coronary arteries (non-atherosclerotic at this stage) leads to ischemic changes in the coronary circulation.

The stiffening and fibrosis of myocardium leads to incipient hypertrophy and deviations in diastolic filling and systolic dysfunction.

The thickening of vasa recta and arcuate arteries in the kidney contribute to mild disregulation of auto regulation, glomerular tubular balance, and salt and water handling.

Thickening of pancreatic vessels may contribute to deviation in insulin sensitivity and resistance.

The proposed genesis of fibrotic and proliferative changes in cardiovascular-renal tissues, independently of blood pressure levels in prehypertension (before the onset of systole-diastolic hypertension) provides answers to some age old enigmas and controversies:

The old controversy, with vast literature, on the question of whether structural changes in the vasculature always result from hypertension or can be the cause of it also, can now be answered.

The observation in the SHR describing the appearance of mild cardiac hypertrophy before the onset of hypertension can now be explained.

Incipient abnormalities in renal handling of salt and water excretion can occur before the onset of established hypertension.

Importantly, the incidence of ischemic coronary disease, before the onset of hypertension, finally explains the enigmatic results of the original VA Trials on the treatment of hypertension showing that reduction of blood pressure by anti-hypertensive treatment prevented the pressure dependent complications of hypertension, but did not significantly alter the incidence of coronary artery disease.

\section{Perspectives}

This is not an attempt at the impossible task to review the vast literature on the etiology of the hypertensive cardiovascular-renal disease. Only selected references are cited to support the evidence based hypothesis, which we believe is the first of its kind in scope. The 
multiple forms of Erb receptors, as well as the multiple agonists for the EGFR, are not discussed as their differential or specific role in health and disease are not well explored.

Scientific truth is not revealed in the armchair it has to be sought by investigative inquiry. Nevertheless, it is submitted that a comprehensive hypothesis, howsoever imperfect, can be an enormous stimulus for further research on a complex subject - an avenue we believe has not been exploited sufficiently.

The proposal that an enhanced level of agonist independent actions of EGFR can mediate the initiation and progression of HCVRD by causing non-tumorous proliferative changes in cardiovascular-renal tissues has ample support in the biochemical, if not the clinical literature [7,23,53-55,165]. The validity of the hypothesis, however, depends upon the vital physiological role which the hypothesis assigns to the agonist EGF and which has not been, hitherto, recognized or articulated.

If the proposed role for EGF is confirmed in essential detail, the hypothesis can answer questions that investigators in the field have been searching for more than 200 years. If not, this will not be the first "swan song" of an emeritus to die its own death.

\section{Acknowledgements}

In preparation of the manuscript, the essential and capable help of Mrs. Katherine Jerger is gratefully acknowledged. The author is also grateful to Drs. Sumeet Chugh and Tom Peter for their generous help and advice to make it happen. A deep inner gratitude is expressed to my late wife, Dr. Minno Sambhi, for inspiration and the sustaining support for the arduous task.

\section{References}

1. Weder $A B$ (2007) Evolution and hypertension. Hypertension 49: 260-265.

2. Stocks T, Van Hemelrijck M, Manjer J, Bjørge T, Ulmer H, et al. (2012) Blood pressure and risk of cancer incidence and mortality in the Metabolic Syndrome and Cancer Project. Hypertension 59: 802-810.

3. Arai K-I, Sporn MB, Roberts AB and Battey JF (1990) Peptide growth factors and their receptors, Springer-Verlag, Berlin; New York.

4. Guyton AC, Hall JE, Coleman TG and Manning Jr RD (1990) The dominant role of the kidneys in the long term regulation of arterial pressure in normal and hypertensive states, Raven Press, Ltd., New York.

5. Johnson RJ, Rodriguez-Iturbe B, Nakagawa T, Kang DH, Feig DI, et al. (2005) Subtle renal injury is likely a common mechanism for saltsensitive essential hypertension. Hypertension 45: 326-330.

6. Rettig R, Grisk O (2005) The kidney as a determinant of genetic hypertension: evidence from renal transplantation studies. Hypertension 46: 463-468.

7. Carpenter G (1999) Employment of the epidermal growth factor receptor in growth factor-independent signaling pathways. J Cell Biol 146: 697-702.

8. Swaminathan N and Sambhi MP (1991) Increased epidermal growth factor receptor levels in the adult SHR kidney.

9. Sambhi MP, Swaminathan N, Wang H and Rong HM (1992) Upregulation of adrenal, renal and vascular growth factors in salt fed hypertensive Dahl rats, John Libbey Eurotext Ltd., Colloque INSERM.

10. Krug AW, Grossmann C, Schuster C, Freudinger R, Mildenberger S, et al. (2003) Aldosterone stimulates epidermal growth factor receptor expression. J Biol Chem 278: 43060-43066.
11. Prieto-Carrasquero MC, Botros FT, Pagan J, Kobori H, Seth DM, et al. (2008) Collecting duct renin is upregulated in both kidneys of 2-kidney, 1-clip goldblatt hypertensive rats. Hypertension 51: 1590-1596.

12. Shapiro JI, Dial LD (2012) How safe is unilateral nephrectomy? Hypertension 60: 1383-1384.

13. Rodríguez-Gómez I, Wangensteen R, Pérez-Abud R, Quesada A, Del Moral RG, et al. (2012) Long-term consequences of uninephrectomy in male and female rats. Hypertension 60: 1458-1463.

14. TOBIAN L, COFFEE K, FERREIRA D, MEULI J (1964) THE EFFECT OF RENAL PERFUSION PRESSURE ON THE NET TRANSPORT OF SODIUM OUT OF DISTAL TUBULAR URINE AS STUDIED WITH THE STOP-FLOW TECHNIQUE. J Clin Invest 43: 118-128.

15. Komolova M, Adams MA (2010) Moment-to-moment characteristics of the relationship between arterial pressure and renal interstitial hydrostatic pressure. Hypertension 56: 650-657.

16. Orr AW, Helmke BP, Blackman BR, Schwartz MA (2006) Mechanisms of mechanotransduction. Dev Cell 10: 11-20.

17. Lucas J, Floyer MA (1973) Renal control of changes in the compliance of the interstitial space: a factor in the aetiology of renoprival hypertension. Clin Sci 44: 397-416.

18. Lucas J, Floyer MA (1974) Changes in body fluid distribution and interstitial tissue complicance during the development and reversal of experimental renal hypertension in the rat. Clin Sci Mol Med 47: 1-11.

19. Schoenwaelder SM, Burridge K (1999) Bidirectional signaling between the cytoskeleton and integrins. Curr Opin Cell Biol 11:274-286.

20. Humphrey JD (2008) Mechanisms of arterial remodeling in hypertension: coupled roles of wall shear and intramural stress. Hypertension 52: 195-200.

21. Bershadsky A, Kozlov M, Geiger B (2006) Adhesion-mediated mechanosensitivity: a time to experiment, and a time to theorize. Curr Opin Cell Biol 18: 472-481.

22. Schwartz MA, DeSimone DW (2008) Cell adhesion receptors in mechanotransduction. Curr Opin Cell Biol 20: 551-556.

23. Schwartz MA, Baron V (1999) Interactions between mitogenic stimuli, or, a thousand and one connections. Curr Opin Cell Biol 11: 197-202.

24. Shah BH, Catt KJ (2003) A central role of EGF receptor transactivation in angiotensin II -induced cardiac hypertrophy. Trends Pharmacol Sci 24: 239-244.

25. Odenbach J, Wang X, Cooper S, Chow FL, Oka T, et al. (2011) MMP-2 mediates angiotensin II-induced hypertension under the transcriptional control of MMP-7 and TACE. Hypertension 57: 123-130.

26. Schmid-Schönbein GW (2011) Matrix metalloproteinases activities in hypertension: emerging opportunities. Hypertension 57: 24-25.

27. Suzuki H, Eguchi S (2006) Growth factor receptor transactivation in mediating end organ damage by angiotensin II. Hypertension 47: 339-340.

28. Rude MK, Duhaney TA, Kuster GM, Judge S, Heo J, et al. (2005) Aldosterone stimulates matrix metalloproteinases and reactive oxygen species in adult rat ventricular cardiomyocytes. Hypertension 46: 555-561.

29. Brassard P, Amiri F, Schiffrin EL (2005) Combined angiotensin II type 1 and type 2 receptor blockade on vascular remodeling and matrix metalloproteinases in resistance arteries. Hypertension 46: 598-606.

30. Fagard RH (2008) Influencing the natural history of hypertension: it is the blood pressure achieved more than the drug. J Hypertens 26: 1533-1535.

31. Carey RM (2013) Resistant hypertension. Hypertension 61: 746-750.

32. Harris RC, Hoover RL, Jacobson HR, Badr KF (1988) Evidence for glomerular actions of epidermal growth factor in the rat. J Clin Invest 82: 1028-1039.

33. Uchihashi M, Hirata Y, Fujita T, Matsukura S (1982) Age-related decrease of urinary excretion of human epidermal growth factor (hEGF). Life Sci 31: 679-683.

34. Gregory H, Holmes JE, Willshire IR (1977) Urogastrone levels in the urine of normal adult humans. J Clin Endocrinol Metab 45: 668-672. 
35. Fisher DA, Salido EC, Barajas L (1989) Epidermal growth factor and the kidney. Annu Rev Physiol 51: 67-80.

36. Zhu HJ, Iaria J, Orchard S, Walker F, Burgess AW (2003) Epidermal growth factor receptor: association of extracellular domain negatively regulates intracellular kinase activation in the absence of ligand. Growth Factors 21: 15-30

37. Carpenter G (1987) Receptors for epidermal growth factor and other polypeptide mitogens. Annu Rev Biochem 56: 881-914.

38. Hayashida W, Horiuchi M, Dzau VJ (1996) Intracellular third loop domain of angiotensin II type-2 receptor. Role in mediating signal transduction and cellular function. J Biol Chem 271: 21985-21992.

39. Wang C, Jayadev S, Escobedo JA (1995) Identification of a domain in the angiotensin II type 1 receptor determining Gq coupling by the use of receptor chimeras. J Biol Chem 270: 16677-16682.

40. de Gasparo M, Catt KJ, Inagami T, Wright JW, Unger T (2000) International union of pharmacology. XXIII. The angiotensin II receptors. Pharmacol Rev 52: 415-472.

41. Kamer AR, Sacks PG, Vladutiu A, Liebow C (2004) EGF mediates multiple signals: dependence on the conditions. Int J Mol Med 13: 143-147.

42. Carpenter G, Cohen S (1976) Human epidermal growth factor and the proliferation of human fibroblasts. J Cell Physiol 88: 227-237.

43. Volpe M, Musumeci B, De Paolis P, Savoia C, Morganti A (2003) Angiotensin II AT2 receptor subtype: an uprising frontier in cardiovascular disease? J Hypertens 21: 1429-1443.

44. De Paolis P, Porcellini A, Savoia C, Lombardi A, Gigante B, et al. (2002) Functional cross-talk between angiotensin II and epidermal growth factor receptors in NIH3T3 fibroblasts. J Hypertens 20: 693-699.

45. Carey RM (2005) Cardiovascular and renal regulation by the angiotensin type 2 receptor: the AT2 receptor comes of age. Hypertension 45: 840-844.

46. Ichiki $\mathrm{T}$, Kambayashi $\mathrm{Y}$, Inagami $\mathrm{T}$ (1995) Multiple growth factors modulate mRNA expression of angiotensin II type-2 receptor in R3T3 cells. Circ Res 77: 1070-1076.

47. Ozono R, Wang ZQ, Moore AF, Inagami T, Siragy HM, et al. (1997) Expression of the subtype 2 angiotensin (AT2) receptor protein in rat kidney. Hypertension 30: 1238-1246.

48. Sampson AK, Moritz KM, Jones ES, Flower RL, Widdop RE, et al. (2008) Enhanced angiotensin II type 2 receptor mechanisms mediate decreases in arterial pressure attributable to chronic low-dose angiotensin II in female rats. Hypertension 52: 666-671.

49. Good DW (2007) Nongenomic actions of aldosterone on the renal tubule. Hypertension 49: 728-739.

50. Funder JW (2009) Reconsidering the roles of the mineralocorticoid receptor. Hypertension 53: 286-290.

51. Adler GK, Williams GH (2007) Aldosterone: villain or protector? Hypertension 50: 31-32.

52. Touyz RM, Wu XH, He G, Salomon S, Schiffrin EL (2002) Increased angiotensin II-mediated Src signalling via epidermal growth factor receptor transactivation is associated with decreased C-terminal Src kinase activity in vascular smooth muscle cells from spontaneously hypertensive rats. Hypertension 39: 479-485.

53. Moghal N, Sternberg PW (1999) Multiple positive and negative regulators of signaling by the EGF-receptor. Curr Opin Cell Biol 11: 190-196.

54. Hackel PO, Zwick E, Prenzel N, Ullrich A (1999) Epidermal growth factor receptors: critical mediators of multiple receptor pathways. Curr Opin Cell Biol 11: 184-189.

55. Luttrell LM, Daaka Y, Lefkowitz RJ (1999) Regulation of tyrosine kinase cascades by G-protein-coupled receptors. Curr Opin Cell Biol 11: 177-183.

56. Swynghedauw B (2003) Adrenomedullin: a new member of the vasoactive peptide family with trophic action. J Hypertens 21: 1085-1086.

57. Olivares-Reyes JA, Shah BH, Hernández-Aranda J, García-Caballero A, Farshori MP, et al. (2005) Agonist-induced interactions between angiotensin AT1 and epidermal growth factor receptors. Mol Pharmacol 68: 356-364.

58. Wakui H, Tamura K, Tanaka Y, Matsuda M, Bai Y, et al. (2010) Cardiacspecific activation of angiotensin II type 1 receptor-associated protein completely suppresses cardiac hypertrophy in chronic angiotensin IIinfused mice. Hypertension 55: 1157-1164.

59. Smith NJ, Luttrell LM (2006) Signal switching, crosstalk, and arrestin scaffolds: novel G protein-coupled receptor signaling in cardiovascular disease. Hypertension 48: 173-179.

60. Henrion D (2012) Why do we need a selective angiotensin II type 2 receptor agonist? Hypertension 60: 616-617.

61. Verdonk K, Durik M, Abd-Alla N, Batenburg WW, van den Bogaerdt AJ, et al. (2012) Compound 21 induces vasorelaxation via an endotheliumand angiotensin II type 2 receptor-independent mechanism. Hypertension 60: 722-729.

62. Abadir PM, Periasamy A, Carey RM, Siragy HM (2006) Angiotensin II type 2 receptor-bradykinin $\mathrm{B} 2$ receptor functional heterodimerization. Hypertension 48: 316-322.

63. D'Amore A, Black MJ, Thomas WG (2005) The angiotensin II type 2 receptor causes constitutive growth of cardiomyocytes and does not antagonize angiotensin II type 1 receptor-mediated hypertrophy. Hypertension 46: 1347-1354.

64. Reudelhuber TL (2005) The continuing saga of the AT2 receptor: a case of the good, the bad, and the innocuous. Hypertension 46: 1261-1262.

65. Ferreira AJ, Santos RA, Bradford CN, Mecca AP, Sumners C, et al. (2010) Therapeutic implications of the vasoprotective axis of the reninangiotensin system in cardiovascular diseases. Hypertension 55: 207-213.

66. Gomes ER, Lara AA, Almeida PW, Guimarães D, Resende RR, et al. (2010) Angiotensin-(1-7) prevents cardiomyocyte pathological remodelling through a nitric oxide/guanosine 3',5'-cyclic monophosphate-dependent pathway. Hypertension 55: 153-160.

67. Turner AJ (2008) Angiotensin-converting enzyme 2: cardioprotective player in the renin-angiotensin system? Hypertension 52: 816-817.

68. Iwai M, Nakaoka H, Senba I, Kanno H, Moritani T, et al. (2012) Possible involvement of angiotensin-converting enzyme 2 and Mas activation in inhibitory effects of angiotensin II Type 1 receptor blockade on vascular remodelling. Hypertension 60: 137-144.

69. Gironacci MM, Adamo HP, Corradi G, Santos RA, Ortiz P, et al. (2011) Angiotensin (1-7) induces MAS receptor internalization. Hypertension 58: 176-181.

70. Kemp BA, Bell JF, Rottkamp DM, Howell NL, Shao W, et al. (2012) Intrarenal angiotensin III is the predominant agonist for proximal tubule angiotensin type 2 receptors. Hypertension 60: 387-395.

71. Fujita M, Minamino T, Asanuma H, Sanada S, Hirata A, et al. (2005) Aldosterone nongenomically worsens ischemia via protein kinase Cdependent pathways in hypoperfused canine hearts. Hypertension 46: 113-117.

72. Wehling M (2005) Rapid effects of aldosterone: relevant in cardiac ischemia? Hypertension 46: 27-28.

73. Schmidt BM, Sammer U, Fleischmann I, Schlaich M, Delles C, et al. (2006) Rapid nongenomic effects of aldosterone on the renal vasculature in humans. Hypertension 47: 650-655.

74. Uhrenholt TR, Schjerning J, Hansen PB, Nørregaard R, Jensen BL, et al. (2003) Rapid inhibition of vasoconstriction in renal afferent arterioles by aldosterone. Circ Res 93: 1258-1266.

75. Savard S, Amar L, Plouin PF, Steichen O (2013) Cardiovascular complications associated with primary aldosteronism: a controlled crosssectional study. Hypertension 62: 331-336.

76. Muiesan ML, Salvetti M, Paini A, Agabiti-Rosei C, Monteduro C, et al. (2008) Inappropriate left ventricular mass in patients with primary aldosteronism. Hypertension 52: 529-534.

77. Díez J (2008) Effects of aldosterone on the heart: beyond systemic hemodynamics? Hypertension 52: 462-464

78. Griol-Charhbili V, Fassot C, Messaoudi S, Perret C, Agrapart V, et al. (2011) Epidermal growth factor receptor mediates the vascular 
dysfunction but not the remodeling induced by aldosterone/salt. Hypertension 57: 238-244.

79. De Giusti VC, Nolly MB, Yeves AM, Caldiz CI, Villa-Abrille MC, et al. (2011) Aldosterone stimulates the cardiac $\mathrm{Na}(+) / \mathrm{H}(+)$ exchanger via transactivation of the epidermal growth factor receptor. Hypertension 58: 912-919.

80. Rickard AJ, Fuller PJ (2011) Mineralocorticoid and epidermal growth factor receptors: partners in vivo. Hypertension 57: 144-145.

81. Rossi GP, Bernini G, Desideri G, Fabris B, Ferri C, et al. (2006) Renal damage in primary aldosteronism: results of the PAPY Study. Hypertension 48: 232-238.

82. Bochud M, Nussberger J, Bovet P, Maillard MR, Elston RC, et al. (2006) Plasma aldosterone is independently associated with the metabolic syndrome. Hypertension 48: 239-245.

83. du Cailar G, Fesler P, Ribstein J, Mimran A (2010) Dietary sodium, aldosterone, and left ventricular mass changes during long-term inhibition of the renin-angiotensin system. Hypertension 56: 865-870.

84. Pimenta E, Calhoun DA (2006) Aldosterone, dietary salt, and renal disease. Hypertension 48: 209-210.

85. Acelajado MC, Pimenta E, Calhoun DA (2010) Salt and aldosterone: a concert of bad effects. Hypertension 56: 804-805.

86. Gonzalez M, Lobos L, Castillo F, Galleguillos L, Lopez NC, et al. (2005) High-salt diet inhibits expression of angiotensin type 2 receptor in resistance arteries. Hypertension 45: 853-859.

87. Alderman MH (2007) Presidential Address: 21st Scientific Meeting of the International Society of Hypertension: dietary sodium and cardiovascular disease: the 'J'-shaped relation. J Hypertens 25: 903-907.

88. Reudelhuber TL (2010) Prorenin, Renin, and their receptor: moving targets. Hypertension 55: 1071-1074.

89. Nguyen G (2006) Renin/prorenin receptors. Kidney Int 69: 1503-1506.

90. Campbell DJ (2008) Critical review of prorenin and (pro)renin receptor research. Hypertension 51: 1259-1264.

91. Nguyen G (2007) The (pro)renin receptor: pathophysiological roles in cardiovascular and renal pathology. Curr Opin Nephrol Hypertens 16: 129-133.

92. Antonipillai I (1993) Epidermal growth factor is a potent inhibitor of renin secretion. Hypertension 21: 654-659.

93. Krebs C, Hamming I, Sadaghiani S, Steinmetz OM, Meyer-Schwesinger $C$, et al. (2007) Antihypertensive therapy upregulates renin and (pro)renin receptor in the clipped kidney of Goldblatt hypertensive rats. Kidney Int 72: 725-730.

94. Siragy HM, Xue C, Abadir P, Carey RM (2005) Angiotensin subtype-2 receptors inhibit renin biosynthesis and angiotensin II formation. Hypertension 45: 133-137.

95. Gonzalez AA, Lara LS, Luffman C, Seth DM, Prieto MC (2011) Soluble form of the (pro)renin receptor is augmented in the collecting duct and urine of chronic angiotensin II-dependent hypertensive rats. Hypertension 57: 859-864.

96. Feldt S, Batenburg WW, Mazak I, Maschke U, Wellner M, et al. (2008) Prorenin and renin-induced extracellular signal-regulated kinase $1 / 2$ activation in monocytes is not blocked by aliskiren or the handle-region peptide. Hypertension 51: 682-688.

97. Rajagopalan S, Bakris GL, Abraham WT, Pitt B, Brook RD (2013) Complete renin-angiotensin-aldosterone system (RAAS) blockade in high-risk patients: recent insights from renin blockade studies. Hypertension 62: 444-449.

98. Zhao D, Seth DM, Navar LG (2009) Enhanced distal nephron sodium reabsorption in chronic angiotensin II-infused mice. Hypertension 54: 120-126.

99. Kohan DE, Rossi NF, Inscho EW, Pollock DM (2011) Regulation of blood pressure and salt homeostasis by endothelin. Physiol Rev 91: 1-77.

100. Speed JS, Pollock DM (2013) Endothelin, kidney disease, and hypertension. Hypertension 61: 1142-1145.
101. Zeng C, Hopfer U, Asico LD, Eisner GM, Felder RA, et al. (2005) Altered AT1 receptor regulation of ETB receptors in renal proximal tubule cells of spontaneously hypertensive rats. Hypertension 46: 926-931.

102. Melenhorst WB, Mulder GM, Xi Q, Hoenderop JG, Kimura K, et al. (2008) Epidermal growth factor receptor signaling in the kidney: key roles in physiology and disease. Hypertension 52: 987-993.

103. Vehaskari VM, Herndon J, Hamm LL (1991) Mechanism of sodium transport inhibition by epidermal growth factor in cortical collecting ducts. Am J Physiol 261: F896-903.

104. Shen JP, Cotton CU (2003) Epidermal growth factor inhibits amiloridesensitive sodium absorption in renal collecting duct cells. Am J Physiol Renal Physiol 284: F57-64.

105. Tong Q, Stockand JD (2005) Receptor tyrosine kinases mediate epithelial $\mathrm{Na}(+)$ channel inhibition by epidermal growth factor. Am J Physiol Renal Physiol 288: F150-161.

106. Grossmann C, Freudinger R, Mildenberger S, Krug AW, Gekle M (2004) Evidence for epidermal growth factor receptor as negative-feedback control in aldosterone-induced $\mathrm{Na}+$ reabsorption. Am J Physiol Renal Physiol 286: F1226-1231.

107. Vassileva I, Mountain C, Pollock DM (2003) Functional role of ETB receptors in the renal medulla. Hypertension 41: 1359-1363.

108. Brunner HR, Laragh JH, Baer L, Newton MA, Goodwin FT, et al. (1972) Essential hypertension: renin and aldosterone, heart attack and stroke. $\mathrm{N}$ Engl J Med 286: 441-449.

109. Resnick LM (1990) The role of dietary calcium and magnesium in the therapy of hypertension, Raven Press, Ltd., New York.

110. Han HJ, Park JY, Lee YJ, Park SH (2003) Effect of epidermal growth factor on phosphate uptake in renal proximal tubule cells: involvement of PKC, MAPK, and cPLA2. Kidney Blood Press Res 26: 315-324.

111. Peppelenbosch MP, Tertoolen LG, de Laat SW (1991) Epidermal growth factor-activated calcium and potassium channels. J Biol Chem 266: 19938-19944.

112. Macara IG (1986) Activation of $45 \mathrm{Ca} 2+$ influx and $22 \mathrm{Na}+\mathrm{H}+$ exchange by epidermal growth factor and vanadate in A431 cells is independent of phosphatidylinositol turnover and is inhibited by phorbol ester and diacylglycerol. J Biol Chem 261: 9321-9327.

113. SMIRK FH, HALL WH (1958) Inherited hypertension in rats. Nature 182: 727-728.

114. Knudsen KD, Dahl LK, Thompson K, Iwai J, Heine M, et al. (1970) Effects of chronic excess salt ingestion. Inheritance of hypertension in the rat. J Exp Med 132: 976-1000.

115. Pickering G (1974) Hypertension: Causes, consequences and management. (2 edn), Churchill Livingstone, London.

116. HAMILTON M, PICKERING GW, ROBERTS JA, SOWRY GS (1954) The aetiology of essential hypertension. 4 . The role of inheritance. Clin Sci (Lond) 13: 273-304.

117. PLATT R (1959) The nature of essential hypertension. Lancet 2: 55-57.

118. Barker DJ, Osmond C, Golding J, Kuh D, Wadsworth ME (1989) Growth in utero, blood pressure in childhood and adult life, and mortality from cardiovascular disease. BMJ 298: 564-567.

119. McMillen IC, Robinson JS (2005) Developmental origins of the metabolic syndrome: prediction, plasticity, and programming. Physiol Rev 85: 571-633.

120. Zandi-Nejad K, Luyckx VA, Brenner BM (2006) Adult hypertension and kidney disease: the role of fetal programming. Hypertension 47: 502-508.

121. Hardy R, Kuh D, Whincup PH, Wadsworth ME (2006) Age at puberty and adult blood pressure and body size in a British birth cohort study. J Hypertens 24: 59-66.

122. Franco MC, Christofalo DM, Sawaya AL, Ajzen SA, Sesso R (2006) Effects of low birth weight in 8- to 13-year-old children: implications in endothelial function and uric acid levels. Hypertension 48: 45-50.

123. Davies AA, Smith GD, May MT, Ben-Shlomo Y (2006) Association between birth weight and blood pressure is robust, amplifies with age, and may be underestimated. Hypertension 48: 431-436. 
124. Primatesta P, Falaschetti E, Poulter NR (2005) Birth weight and blood pressure in childhood: results from the Health Survey for England. Hypertension 45: 75-79.

125. Burke V, Beilin LJ, Blake KV, Doherty D, Kendall GE, et al. (2004) Indicators of fetal growth do not independently predict blood pressure in 8-year-old Australians: a prospective cohort study. Hypertension 43: 208-213.

126. Mamun AA, Lawlor DA, O'Callaghan MJ, Williams GM, Najman JM (2005) Effect of body mass index changes between ages 5 and 14 on blood pressure at age 14: findings from a birth cohort study. Hypertension 45 : 1083-1087.

127. Srinivasan SR, Myers L, Berenson GS (2006) Changes in metabolic syndrome variables since childhood in prehypertensive and hypertensive subjects: the Bogalusa Heart Study. Hypertension 48: 33-39.

128. Wilson PW (2006) Adiposity in youth and blood pressure. Hypertension 48: 21-22.

129. Feig DI, Johnson RJ (2003) Hyperuricemia in childhood primary hypertension. Hypertension 42: 247-252.

130. Drake AJ, Walker BR (2004) The intergenerational effects of fetal programming: non-genomic mechanisms for the inheritance of low birth weight and cardiovascular risk. J Endocrinol 180: 1-16.

131. Harrap SB, Van der Merwe WM, Griffin SA, Macpherson F, Lever AF (1990) Brief angiotensin converting enzyme inhibitor treatment in young spontaneously hypertensive rats reduces blood pressure long-term. Hypertension 16: 603-614.

132. Molteni A, Heffelfinger S, Moulder JE, Uhal B, Castellani WJ (2006) Potential deployment of angiotensin I converting enzyme inhibitors and of angiotensin II type 1 and type 2 receptor blockers in cancer chemotherapy. Anticancer Agents Med Chem 6: 451-460.

133. Uemura H, Nakaigawa N, Ishiguro H, Kubota Y (2005) Antiproliferative efficacy of angiotensin II receptor blockers in prostate cancer. Curr Cancer Drug Targets 5: 307-323.

134. Wang Q, Villeneuve G, Wang Z (2005) Control of epidermal growth factor receptor endocytosis by receptor dimerization, rather than receptor kinase activation. EMBO Rep 6: 942-948.

135. Kim J, Ahn S, Guo R, Daaka Y (2003) Regulation of epidermal growth factor receptor internalization by $G$ protein-coupled receptors. Biochemistry 42: 2887-2894.

136. Habib AA, Chun SJ, Neel BG, Vartanian T (2003) Increased expression of epidermal growth factor receptor induces sequestration of extracellular signal-related kinases and selective attenuation of specific epidermal growth factor-mediated signal transduction pathways. Mol Cancer Res 1: 219-233.

137. Hanke S, Valkova C, Stirnweiss J, Drube S, Liebmann C (2006) Activated EGF receptor may balance ERK-inhibitory network signalling pathways. Cell Signal 18: 1031-1040.

138. Mayawala K, Vlachos DG, Edwards JS (2005) Computational modeling reveals molecular details of epidermal growth factor binding. BMC Cell Biol 6: 41.

139. Sauvant C, Hesse D, Holzinger H, Evans KK, Dantzler WH, et al. (2004) Action of EGF and PGE2 on basolateral organic anion uptake in rabbit proximal renal tubules and hOAT1 expressed in human kidney epithelial cells. Am J Physiol Renal Physiol 286: F774-783.

140. Sauvant C, Holzinger H, Gekle M (2003) Short-term regulation of basolateral organic anion uptake in proximal tubular opossum kidney cells: prostaglandin E2 acts via receptor-mediated activation of protein kinase A. J Am Soc Nephrol 14: 3017-3026.

141. Lee JE, Kim YG, Choi YH, Huh W, Kim DJ, et al. (2006) Serum uric acid is associated with microalbuminuria in prehypertension. Hypertension 47: 962-967

142. Perlstein TS, Gumieniak O, Williams GH, Sparrow D, Vokonas PS, et al (2006) Uric acid and the development of hypertension: the normative aging study. Hypertension 48: 1031-1036.
143. Iwashima Y, Horio T, Kamide K, Rakugi H, Ogihara T, et al. (2006) Uric acid, left ventricular mass index, and risk of cardiovascular disease in essential hypertension. Hypertension 47: 195-202.

144. Viazzi F, Parodi D, Leoncini G, Parodi A, Falqui V, et al. (2005) Serum uric acid and target organ damage in primary hypertension. Hypertension 45: 991-996.

145. Boerner JL, Gibson MA, Fox EM, Posner ED, Parsons SJ, et al. (2005) Estrogen negatively regulates epidermal growth factor (EGF)-mediated signal transducer and activator of transcription 5 signalling in human EGF family receptor-overexpressing breast cancer cells. Molecular endocrinology 19: 2660-70.

146. Flores-Benítez D, Ruiz-Cabrera A, Flores-Maldonado C, Shoshani L, Cereijido M, et al. (2007) Control of tight junctional sealing: role of epidermal growth factor. Am J Physiol Renal Physiol 292: F828-836.

147. Yoshida K, Kanaoka S, Takai T, Uezato T, Miura N, et al. (2005) EGF rapidly translocates tight junction proteins from the cytoplasm to the cell-cell contact via protein kinase C activation in TMK-1 gastric cancer cells. Exp Cell Res 309: 397-409.

148. Blaine EH, Davis JO, Witty RT (1970) Renin release after hemorrhage and after suprarenal aortic constriction in dogs without sodium delivery to the macula densa. Circ Res 27: 1081-1089.

149. Ganong WF, Davis JO, Sambhi MP, ed. (1984) Journal of hypertension supplement. Symposium on control of renin secretion; vol 2, 1:1-153.

150. Ibsen H, Olsen MH, Wachtell K, Borch-Johnsen K, Lindholm LH, et al. (2005) Reduction in albuminuria translates to reduction in cardiovascular events in hypertensive patients: losartan intervention for endpoint reduction in hypertension study. Hypertension 45: 198-202.

151. Klausen KP, Scharling H, Jensen G, Jensen JS (2005) New definition of microalbuminuria in hypertensive subjects: association with incident coronary heart disease and death. Hypertension 46: 33-37.

152. PROCOPA Study Group (2002) Dissociation between blood pressure reduction and fall in proteinuria in primary renal diseas: A randomized double-blind trial. Hypertension 20: 729-737.

153. Berger ED, Bader BD, Ebert C, Risler T, Erley CM (2002) Reduction of proteinuria; combined effects of receptor blockade and low dose angiotensin-converting enzyme inhibition. J Hypertens 20: 739-743.

154. White WB, Duprez D, St Hillaire R, Krause S, Roniker B, et al. (2003) Effects of the selective aldosterone blocker eplerenone versus the calcium antagonist amlodipine in systolic hypertension. Hypertension 41: 1021-1026.

155. Ibsen H, Wachtell K, Olsen MH, Borch-Johnsen K, Lindholm LH, et al. (2004) Does albuminuria predict cardiovascular outcome on treatment with losartan versus atenolol in hypertension with left ventricular hypertrophy? A LIFE substudy. J Hypertens 22: 1805-1811.

156. Yoneda M, Sanada H, Yatabe J, Midorikawa S, Hashimoto S, et al. (2005) Differential effects of angiotensin II type-1 receptor antisense oligonucleotides on renal function in spontaneously hypertensive rats. Hypertension 46: 58-65.

157. Pascual JM, Rodilla E, Gonzalez C, Pérez-Hoyos S, Redon J (2005) Longterm impact of systolic blood pressure and glycemia on the development of microalbuminuria in essential hypertension. Hypertension 45: 1125-1130.

158. Kinlay S, Creager MA, Fukumoto M, Hikita H, Fang JC, et al. (2001) Endothelium-derived nitric oxide regulates arterial elasticity in human arteries in vivo. Hypertension 38: 1049-1053.

159. Ruano MJ, Hernández-Hernando S, Jiménez A, Estrada C, Villalobo A (2003) Nitric oxide-induced epidermal growth factor-dependent phosphorylations in A431 tumour cells. Eur J Biochem 270: 1828-1837.

160. Laviades C, Varo N, Díez J (2000) Transforming growth factor beta in hypertensives with cardiorenal damage. Hypertension 36: 517-522.

161. López B, González A, Varo N, Laviades C, Querejeta R, et al. (2001) Biochemical assessment of myocardial fibrosis in hypertensive heart disease. Hypertension 38: 1222-1226.

162. Koyanagi M, Egashira K, Kubo-Inoue M, Usui M, Kitamoto S, et al. (2000) Role of transforming growth factor-betal in cardiovascular 
Citation: Mohinder P Sambhi (2014) A Single Initiating Cause of Hypertension; Potential for Primary Prevention. J Hypertens 3: 169. doi: 10.4172/2167-1095.1000169

Page 18 of 18

inflammatory changes induced by chronic inhibition of nitric oxide synthesis. Hypertension 35: 86-90.

163. Lim H, Zhu YZ (2006) Role of transforming growth factor-beta in the progression of heart failure. Cell Mol Life Sci 63: 2584-2596.

164. Li D, Chen H, Mehta JL (2001) Angiotensin II via activation of type 1 receptor upregulates expression of endoglin in human coronary artery endothelial cells. Hypertension 38: 1062-1067.
165. Gschwind A, Zwick E, Prenzel N, Leserer M, Ullrich A (2001) Cell communication networks: epidermal growth factor receptor transactivation as the paradigm for interreceptor signal transmission. Oncogene 20: 1594-1600. 